\title{
7 Addressing structural drivers of HIV among young people in Eastern and Southern Africa
}

\author{
Evidence, challenges and \\ recommendations for advancing \\ the field
}

\begin{abstract}
Mitzy Gafos, Tara Beattie, Kirsten Stoebenau, Deborah Baron, Renay Weiner, Joyce Wamoyi, Lebohang Letsela, James Hargreaves, Gerry Mshana, Saidi Kapiga, Anne Stangl, Michelle Remme, Lori Heise and Janet Seeley
\end{abstract}

\section{Introduction}

In 2016, of the 2.1 million adolescents (10-19 years) living with HIV globally, $84 \%$ were in sub-Saharan Africa. In this region, adolescent girls are twice as likely as boys to acquire HIV (UNAIDS, 2018b). This difference between adolescent girls and boys is greatest in Eastern and Southern Africa (ESA), where girls account for $78 \%$ of new infections in adolescents (UNICEF, 2018). In this chapter, we focus on the role of structural factors in exacerbating the risk of HIV among young people (10-24 years) in ESA and the structural interventions that aim to address them. Structural factors can be conceptualized as drivers of risk, which fundamentally shape and influence patterns of risk behaviour, and mediators of risk, which hinder or facilitate an individual's or group's ability to avoid HIV (Parkhurst, 2013).

Young people's primary proximal risk for HIV is sexual behaviour, including unprotected sex and partner selection (Figure 7.1). These risk factors are influenced by interpersonal and individual risks such as transactional sex, gender-based violence and harmful alcohol use. Structural factors function upstream of the individual, interpersonal and proximal determinants of HIV risk, increasing susceptibility to HIV and undermining both biomedical and behavioural prevention efforts (Blankenship et al., 2000; Kippax, 2008; Gupta et al., 2008; Hankins and de Zalduondo, 2010). As shown in Figure 7.1, gender inequality, stigma and discrimination, alcohol availability, lack of economic opportunity, lack of education and poor healthcare access are community-level structural drivers on the pathway to sexual risk behaviour and/ or HIV infection. At the macro level, political, legal, cultural and religious, economic and corporate factors, as well as the social influence of the media, 


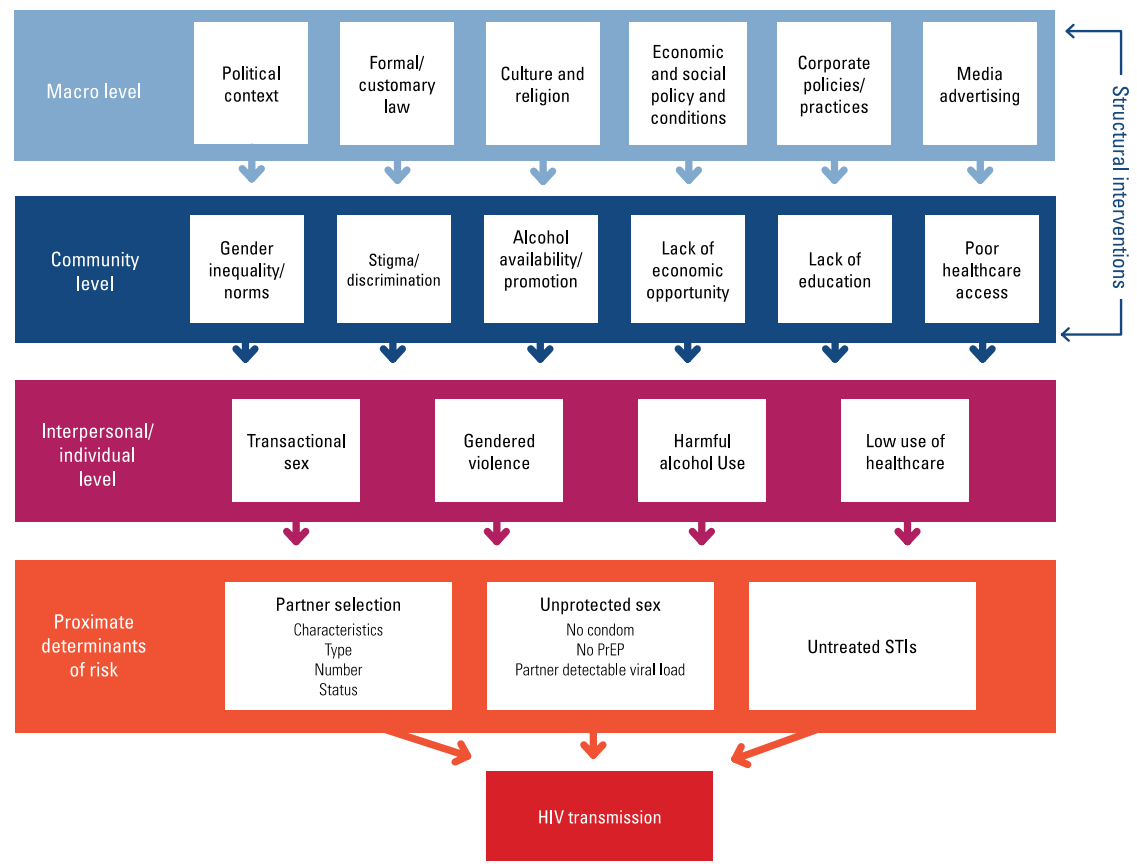

Figure 7.1 STRIVE conceptual framework mapping relationships between HIV, proximal determinants of risk and structural factors (http://strive.lshtm. ac.uk) Colour images available at: https:// tinyurl.com/y5sbppxa

in turn impact on structural drivers of HIV. While these factors serve as drivers for all age groups, the impact on young people is exacerbated by their age and their relatively low social and economic position within society. Young people's experiences during adolescence lay the foundation for adulthood and define trajectories for future generations (Patton et al., 2016). It is therefore important to mitigate the risks posed by the structural drivers of HIV among this age group to improve prospects of future health and well-being.

Structural interventions aim to alter the social, economic and political contexts that influence the drivers or mediators of HIV (Blankenship et al., 2000). Structural interventions may tackle macro-level factors at an institutional level, such as addressing gender inequalities in the criminal justice system or changing the law to prevent child marriage. However, most structural interventions are intended to alter or mitigate drivers of HIV at the community level. As such, structural interventions can address factors such as socio-economic inequalities, harmful gender norms, gender-based violence, alcohol availability and promotion and HIV-related stigma. By targeting factors that increase young people's susceptibility to HIV, structural interventions have the potential to mitigate their risk of HIV. However, 
given that structural interventions function upstream of the proximal risk factors for HIV, they also have the potential to impact on other development outcomes and priorities. It has been argued that these interventions need to be integrated into both HIV prevention programmes and broader gender and development initiatives (Seeley et al., 2012). Addressing the structural drivers of HIV is an essential first step in creating enabling environments for young people to protect themselves from HIV and capitalize on the availability of development opportunities (Hardee et al., 2014). Only by addressing structural drivers will we be able to achieve the 'fast-track to end AIDS' strategic targets and the broader UN Sustainable Development Goals (SDGs) (UN, 2016; UNAIDS, 2015).

A previous literature review evaluated structural interventions among adolescents in sub-Saharan Africa that specifically aimed to change sexual risk behaviours (Wamoyi et al., 2014). The review included economic interventions such as income generation, cash transfer, support to start businesses or find work and support to attend school; gender empowerment interventions that focused on life skills and creating safe spaces for adolescent girls in the community; and behaviour change communication interventions that either provided mass-media information to support social change or to improve parent-child communication. Although a number of the interventions reviewed were then ongoing, there were several that demonstrated positive sexual and reproductive health outcomes especially from economic empowerment interventions. The review highlighted the need for interventions to be designed specifically to address the pathways that influence risk for young people, noting for example that in contrast to a microfinance trial that reduced risk for adult women, the pressures of repaying microcredit loans actually exacerbated risk among young women in one intervention.

In this chapter, we review interventions among young people aged 10-24 in ESA that are designed to impact more broadly on the upstream structural drivers of HIV. We review interventions that address limited livelihood options, including increasing school attendance and attainment, and reducing poverty and gender inequality, including gender norms and gender-based violence. At a time when the SDG agenda has re-focused people's attention on the potential of multi-sectoral action and synergistic developmental opportunities (Fritz and Heise, 2018), we aim to synthesize existing evidence of what works to alter the structural drivers of HIV for young people, identify the challenges of scaling up such interventions and achieving an impact on HIV incidence, and outline recommendations for policy-makers, implementers and researchers.

\section{Causal pathways of risk}

Structural interventions are designed to alter the mechanisms through which upstream structural drivers of HIV influence proximate risk behaviours within specific contexts and populations. These mechanisms of 
influence are delineated as causal pathways to HIV infection. In considering the causal pathways of interest in this review, we summarize evidence on the pathways through which education and poverty, and gender norms and violence, influence the risk of HIV.

\section{Education}

The relationship between education and HIV is thought to have reversed as the HIV epidemic has matured (Hargreaves and Glynn, 2002; Hargreaves et al., 2008). Current evidence suggests that each additional year of school attendance reduces the risk of HIV infection (Barnighausen et al., 2007), which in some studies is particularly pronounced for young women (De Neve et al., 2015; Pettifor et al., 2008). Similarly, evidence demonstrates that higher sexual risk behaviours are associated with being out of school among youth in ESA (Stroeken et al., 2012). Improving school attendance and educational attainment can impact on future socio-economic status; socio-cognitive factors including knowledge, attitudes, self-esteem and selfefficacy; social networks including sexual partnering; personal aspirations; and exposure to HIV prevention education (Jukes et al., 2008a). These factors are likely to play an important role in influencing sexual risk behaviours and adoption of HIV prevention options (Figure 7.2) (Prudden, 2017). There has been growing interest in structural interventions that aim to improve school enrolment, school attendance (as a predictor of school dropout), secondary school completion and educational attainment as a means to reduce the risk of HIV infection, with a particular interest in school-based interventions (Jukes et al., 2008b; Mason-Jones et al., 2016).

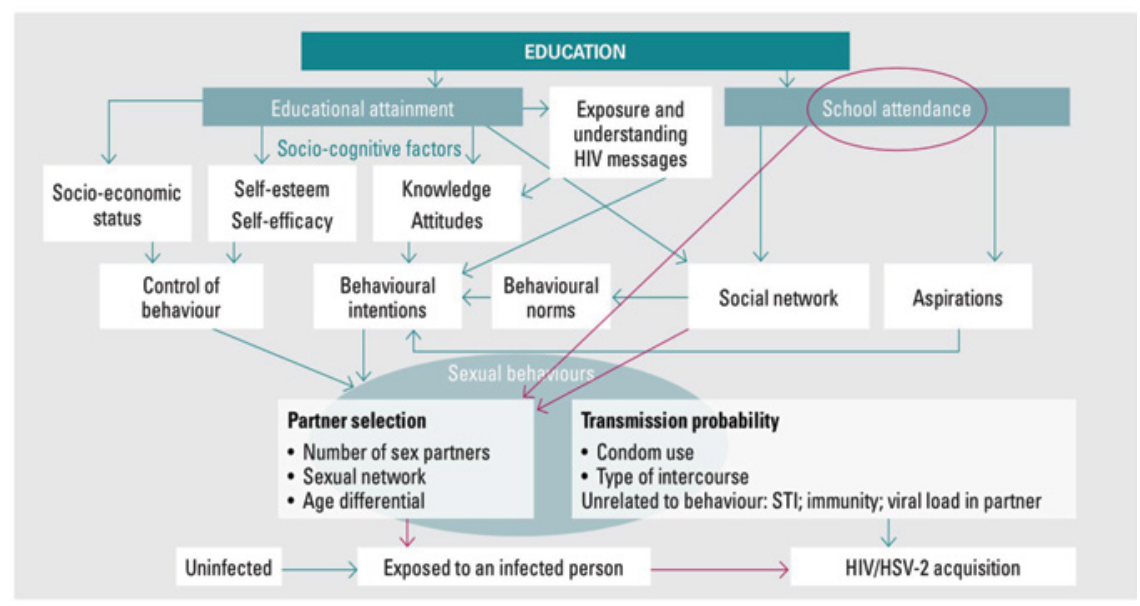

Figure 7.2 Potential pathways of change which may be influenced by greater attendance and greater attainment within schools 


\section{Poverty}

Most reviews of the relationship between poverty and wealth with HIV infection find that macro-level economics, national wealth inequalities and gendered-wealth disparities have both positive and negative impacts on sexual risk behaviours and HIV risk (Wojcicki, 2005; Parkhurst, 2010; Fox, 2010). Certainly, HIV prevalence is highest in the wealthiest subSaharan African countries, although this can mask in-country disparities (Gupta et al., 2008). A number of studies suggest that relative poverty is not associated with HIV, with higher prevalence being observed in households with middle or higher quartile wealth indices (Barnighausen et al., 2007; Mishra et al., 2007). Other studies suggest that increasing socio-economic status either does not increase risk or can decrease sexual risk behaviours in countries with higher per capita income and in-country wealth inequalities (Wojcicki, 2005; Parkhurst, 2010). However, increasing access to resources for women also has the potential to increase risk-taking behaviours in some contexts (Wojcicki, 2005). The relative impact of poverty on HIV risk in different populations is further delineated by gender, marital status for women and urban or rural residency for both women and men (Wojcicki, 2005; Hallman, 2005b; Gillespie et al., 2007). As with education, there is a suggestion of a reversal in relationship between poverty and HIV risk in some countries, with declining prevalence in wealthy groups and increasing prevalence in poorer groups, especially among young women (Hargreaves, 2002; Hallman, 2005b; Parkhurst, 2010).

As shown in Figure 7.3, poverty can impact on HIV risk in terms of members of households being unable to meet the costs of food security, educational expenses and healthcare costs, which in turn influences young peoples' school attendance, health and well-being and engagement in gender-inequitable relationships (Parkhurst, 2013). There is currently increased attention to the role of youth poverty as an economic motivator of inequitable age-disparate and transactional sex relationships (Luke, 2003, 2005). A recent phylogenetic study in a hyperendemic area of South Africa highlighted the extent to which sexual partnering between young women and older men is driving new HIV infections among young women (de Oliveira et al., 2017). Transactional sexual relationships have been shown to be motivated by the desire for sexual relationships to meet basic financial needs and improve social status as well as sociocultural material expressions of love (Stoebenau et al., 2016). There has also been specific attention paid to the negative impact of household poverty on sexual risk behaviour for orphaned youth (Hallman, 2005a).

There is increasing interest in interventions that aim to alleviate poverty among groups for whom it has been shown to increase the risk of HIV. The UNAIDS fast-track target aims to strengthen HIV-sensitive national social 


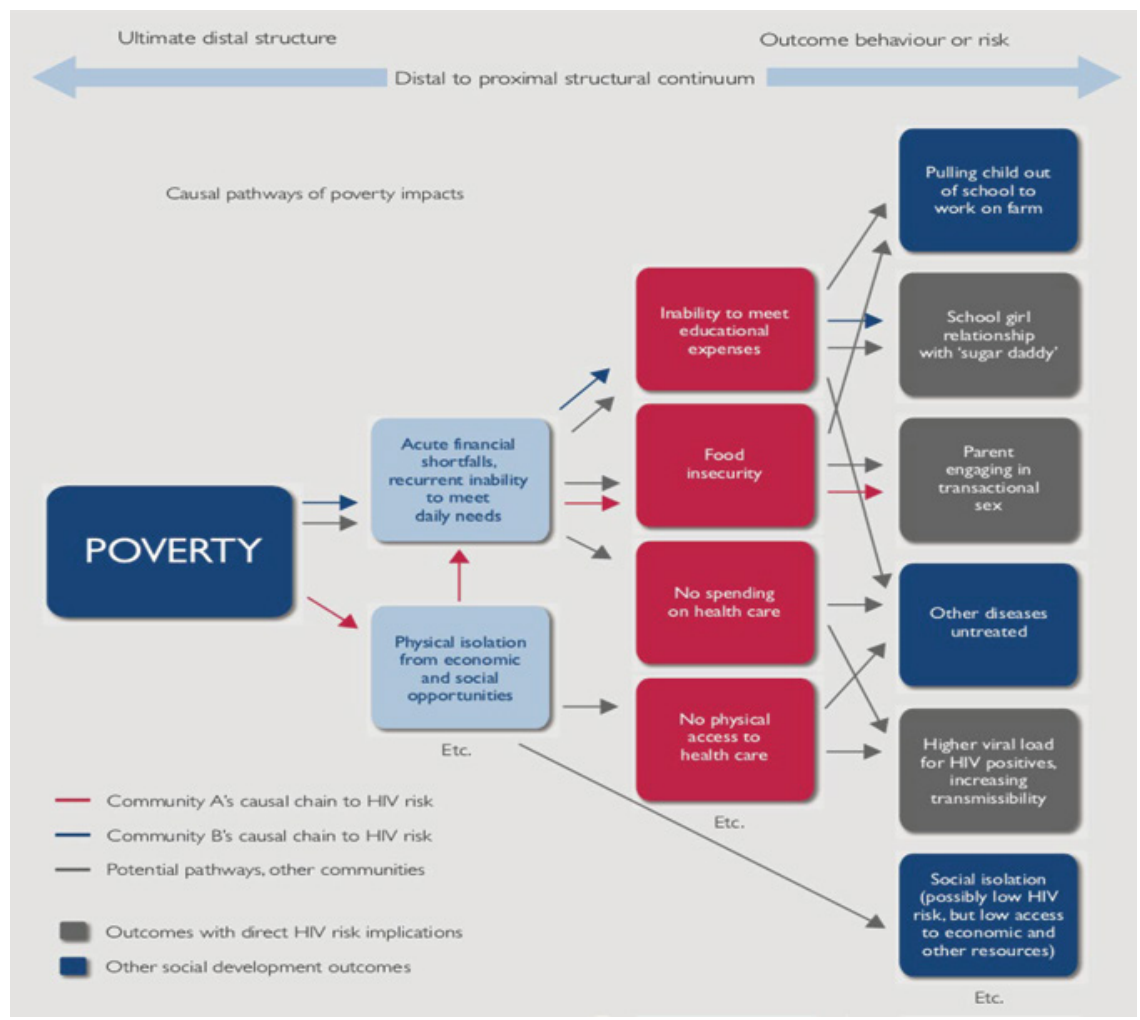

Figure 7.3 Potential pathways through which poverty impacts on HIV risk Figure available in colour at: https:// tinyurl.com/y5sbppxa

and child protection systems to ensure $75 \%$ of people living with or at risk of HIV have access to social protection (UNAIDS, 2018a). Social protection interventions focus on ways to mitigate the impact of poverty, such as conditional and unconditional cash transfer programmes, income generation programmes such as vocational training and work generation, and microfinance programmes as standalone schemes or integrated in health programmes (Heise et al., 2013; Pega et al., 2017; Taaffe et al., 2016; Taaffe et al., 2017; Wilson, 2015; Kennedy et al., 2014; Lorenzetti et al., 2017).

\section{Gender norms and gender-based violence}

The causal pathways between gender-based violence and HIV are multifaceted and complex (Heise and McGrory, 2016). A number of studies have 
shown that young and adult women who experience physical and emotional intimate partner violence (IPV) are more likely to be HIV-positive than women who do not (Durevall and Lindskog, 2015a; Jewkes et al., 2010). However, a meta-analysis across ten countries in sub-Saharan Africa did not observe a link between sexual IPV and HIV among married women, suggesting that other indirect pathways are more influential (Durevall and Lindskog, 2015a). Similarly, studies have shown that men who are violent share a clustering of risk factors that increase their likelihood of being HIVpositive (Jewkes et al., 2011; Decker et al., 2009; Dunkle and Decker, 2013). The clustering of risk factors includes having multiple and concurrent partners; engagement in commercial sex, transactional sex, condomless sex and anal sex; and binge drinking (Dunkle et al., 2006; Dunkle and Decker, 2013; Gass et al., 2011; Gibbs et al., 2017; Durevall and Lindskog, 2015b). In addition, social norms of masculinity and femininity that reproduce the unequal position of women in society and associate masculinity with sexual risk-taking serve as upstream drivers of male IPV perpetration (Jewkes et al., 2010; Harrison et al., 2006).

Social norms are rules of behaviour shared by people in a given society that define what is 'normal' and appropriate behaviour. Social norms that discriminate against women, such as considering the education of boys more important than of girls, or norms which are harmful, such as norms supporting IPV, can exacerbate young women's risk of HIV. Social norms do not mandate behaviours such as IPV but by normalizing the practice can help maintain it, limiting women's ability to resist and community members' ability to intervene (Jewkes et al., 2015). Overall, young and adult women in relationships with violent men are at increased risk of being exposed to HIV and are least able to insist on safer sex practices (Durevall and Lindskog, 2015b; Kacanek et al., 2013).

Figure 7.4 illustrates how the causal pathways of IPV function through socio-economic insecurity, gender inequality and social norms condoning violence to influence sexual risk behaviours and HIV (Heise and McGrory, 2016). There has been increased interest in shifting harmful gender norms as a mechanism of effect on the pathway to the combined risks of genderbased violence and HIV (Cislaghi and Heise, 2016; Cislaghi et al., 2018). A number of reviews have evaluated the evidence of interventions to prevent violence, including for adolescents (De Koker et al., 2014; Lundgren and Amin, 2015; Maman et al., 2000; McCloskey et al., 2016; Shai and Sikweyiya, 2015). As mentioned earlier, there has been increasing interest in social protection interventions to address the upstream influences of poverty on gender-based violence. Gender transformative components such as gender equality training and gender empowerment programmes are increasingly being added to social protection interventions in order to change gender norms condoning violence; empower women socially, economically and politically in society; and address gender inequalities (Gibbs 
Potential pathways between intimate partner violence and women's risk of HIV acquisition

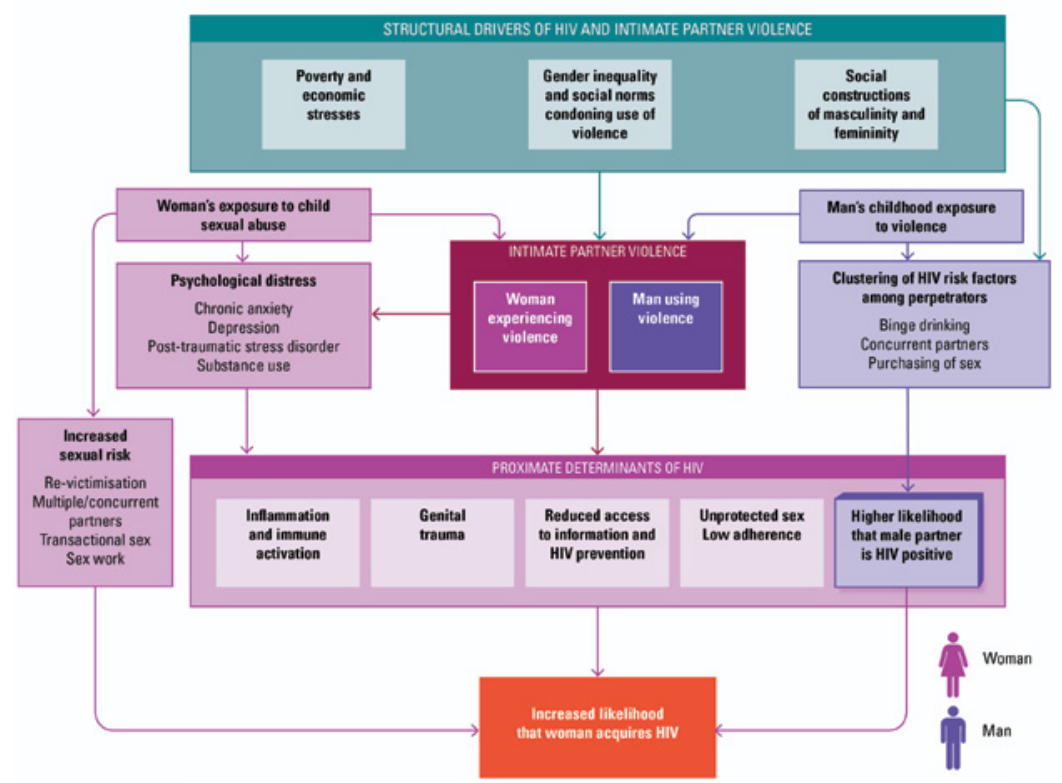

Figure 7.4 Potential pathways between intimate partner violence and women's risk of HIV acquisition Figure available in colour at: https://tinyurl.com/y5sbppxa

et al., 2012; Dworkin et al., 2013; Jewkes et al., 2015; Svanemyr et al., 2015; Buller et al., 2018).

\section{Methods}

In this study we review and synthesize findings from structural interventions among adolescents and young people in ESA. Between 8 and 16 January 2018 we conducted a systematic search of literature in Medline, Embase, Global Health, CINAHL Plus, Africa-Wide Information, PsycINFO, Web of Science Core Collection, Cochrane Library, and Scopus. The literature search was constructed using five concepts: young people (aged 10-24), structural drivers (livelihood, education, poverty, gender, social norms and gender-based violence), HIV prevention, ESA and intervention studies. The inclusion criteria were (1) English language publication; (2) interventions or evaluations of interventions addressing at least one structural driver of interest; (3) comparative evaluations or prepost intervention evaluation; (4) publications from beginning of search engine records to January 2018; and (5) published literature only, based 
on the breadth of the review and the fact that we did not plan to do a systematic review of the literature or conduct a quality assessment. HIV endpoints were not part of the inclusion criteria. The search identified 2458 unique titles. After screening out 2386 references based on title and abstract, we reviewed 72 papers in full reporting on interventions. In total, 40 papers reporting on 27 interventions were included in the review. Interventions were identified from seven countries in ESA. A full description of the literature search methodology is available on request. This review and synthesis of the evidence was conducted by the STRIVE Research Programme Consortium, which aims to deliver new evidence, together with a synthesis of existing evidence, on individual and interrelated structural drivers of HIV, pathways of risk and infection, effective measurement tools of structural drivers and evaluation of structural interventions (http://strive.lshtm.ac.uk).

\section{What we know about the effectiveness of interventions to address structural drivers of HIV}

We now focus on the effectiveness of interventions to address (1) limited livelihood options including education and poverty and (2) gender inequalities including harmful gender norms and gender-based violence. We categorize the interventions based on their primary focus but crossreference interventions that address multiple structural drivers. Tables 7.1 and 7.2 present an overview of the limited livelihood interventions, and Table 7.3 presents an overview of the gender inequalities interventions. Of the 27 interventions reviewed, 11 reported on improving school attendance, 7 on reducing poverty, 5 on reducing GBV and 4 on changing social norms. All interventions specifically aimed to intervene on the causal pathway between structural driver and HIV infection, yet most did not include HIV outcomes. Most interventions reported on multiple outcome measures. Figure 7.5 illustrates interventions that effectively impacted on structural drivers (education, poverty, social norms, GBV), sexual behaviour and clinical outcomes.

\section{Addressing limited livelihood options to reduce HIV risk}

We identified 11 interventions to improve school attendance, 5 to alleviate the impact of poverty more broadly and 2 that evaluated the impact of government cash transfer grants (Tables 7.1 and 7.2).

\section{School attendance: $O V C$}

Seven of the 11 education interventions focused on orphans and vulnerable children (OVC) aged 8-25 in Kenya, Zambia, Zimbabwe and Uganda. 


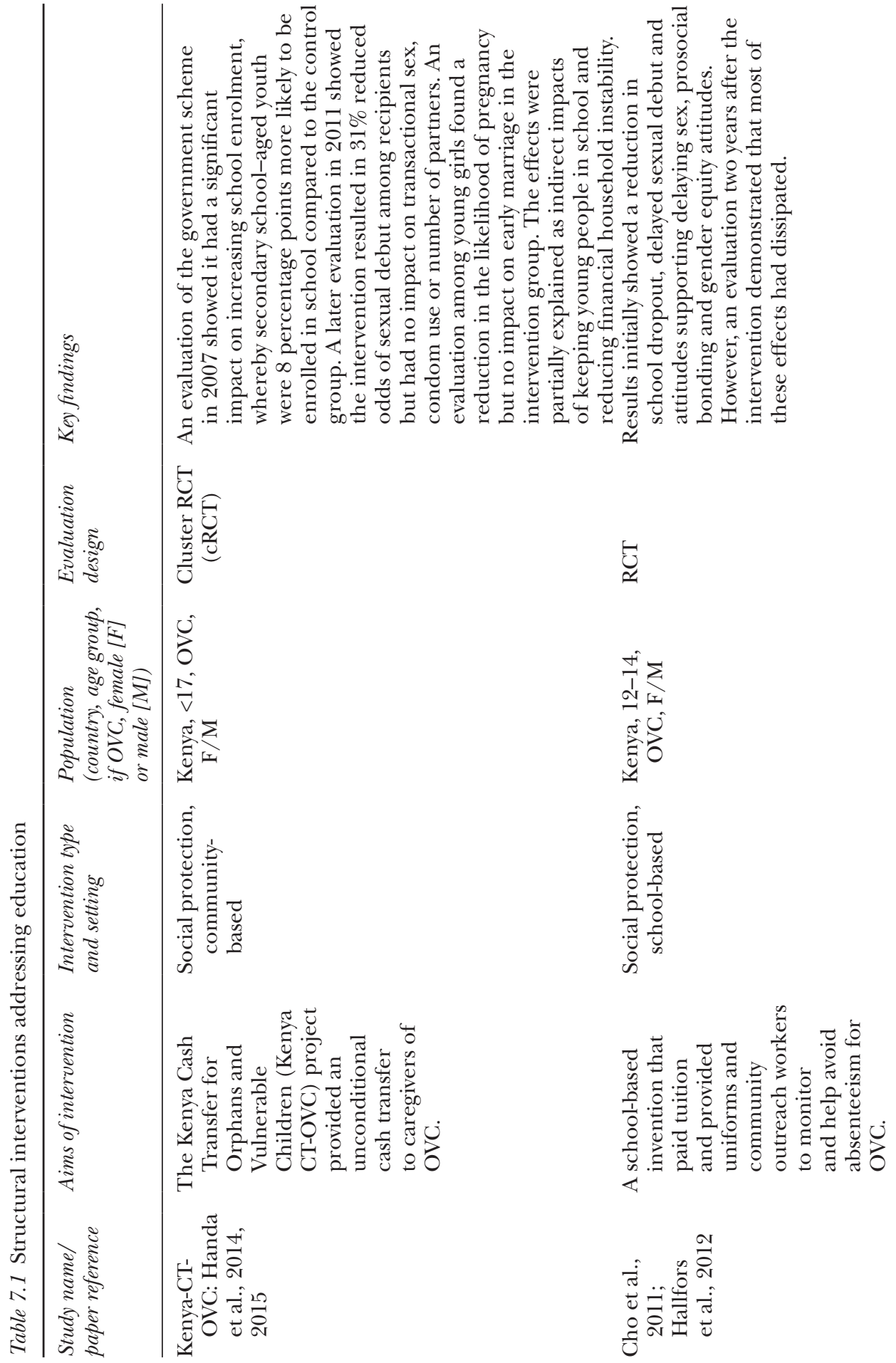




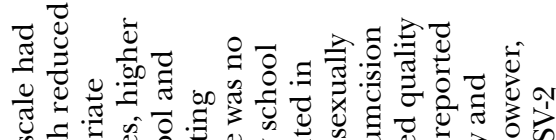

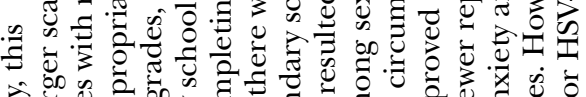

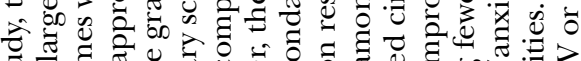

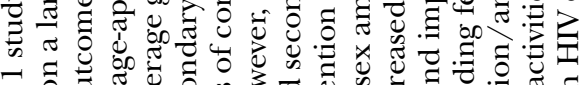

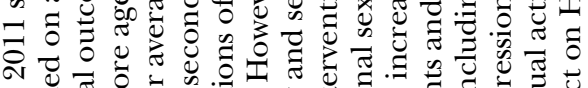
论 $\begin{gathered}0 \\ 0\end{gathered}$

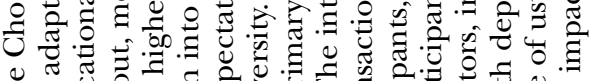

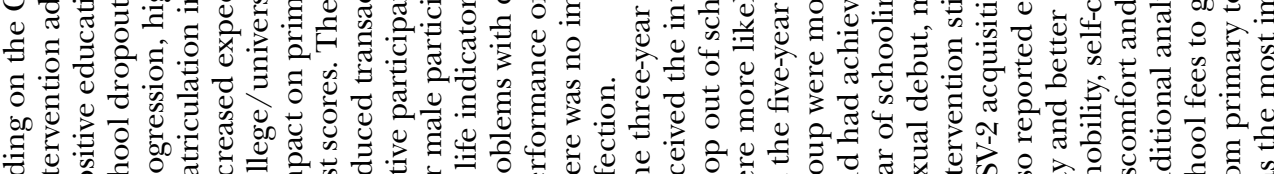

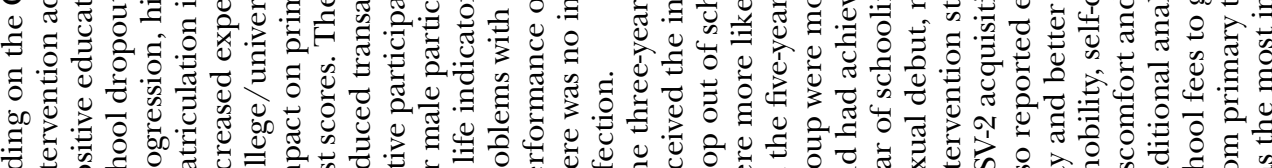

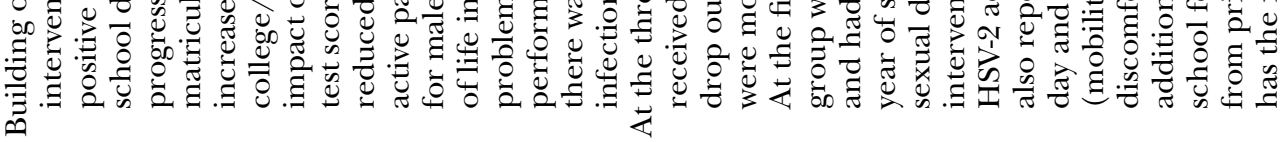

氙

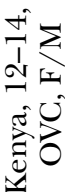

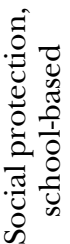

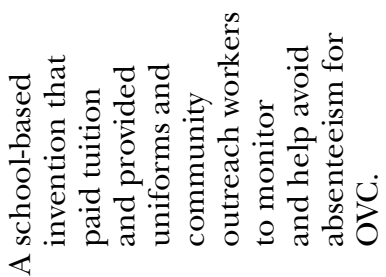

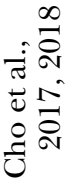

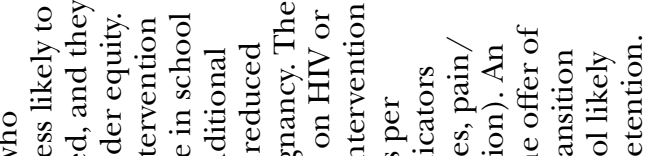

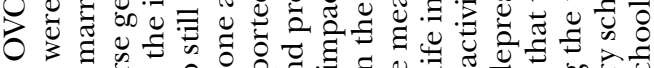

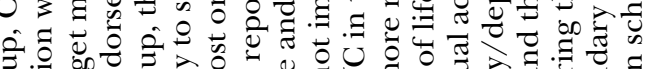

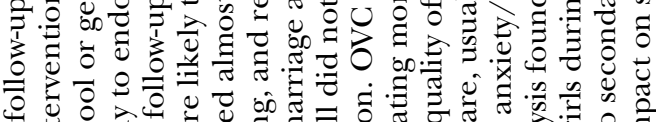
눙

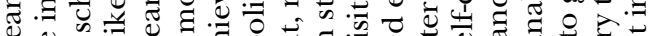
\& ijo

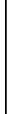

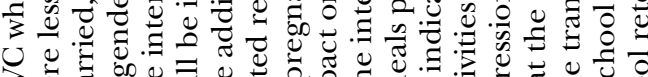




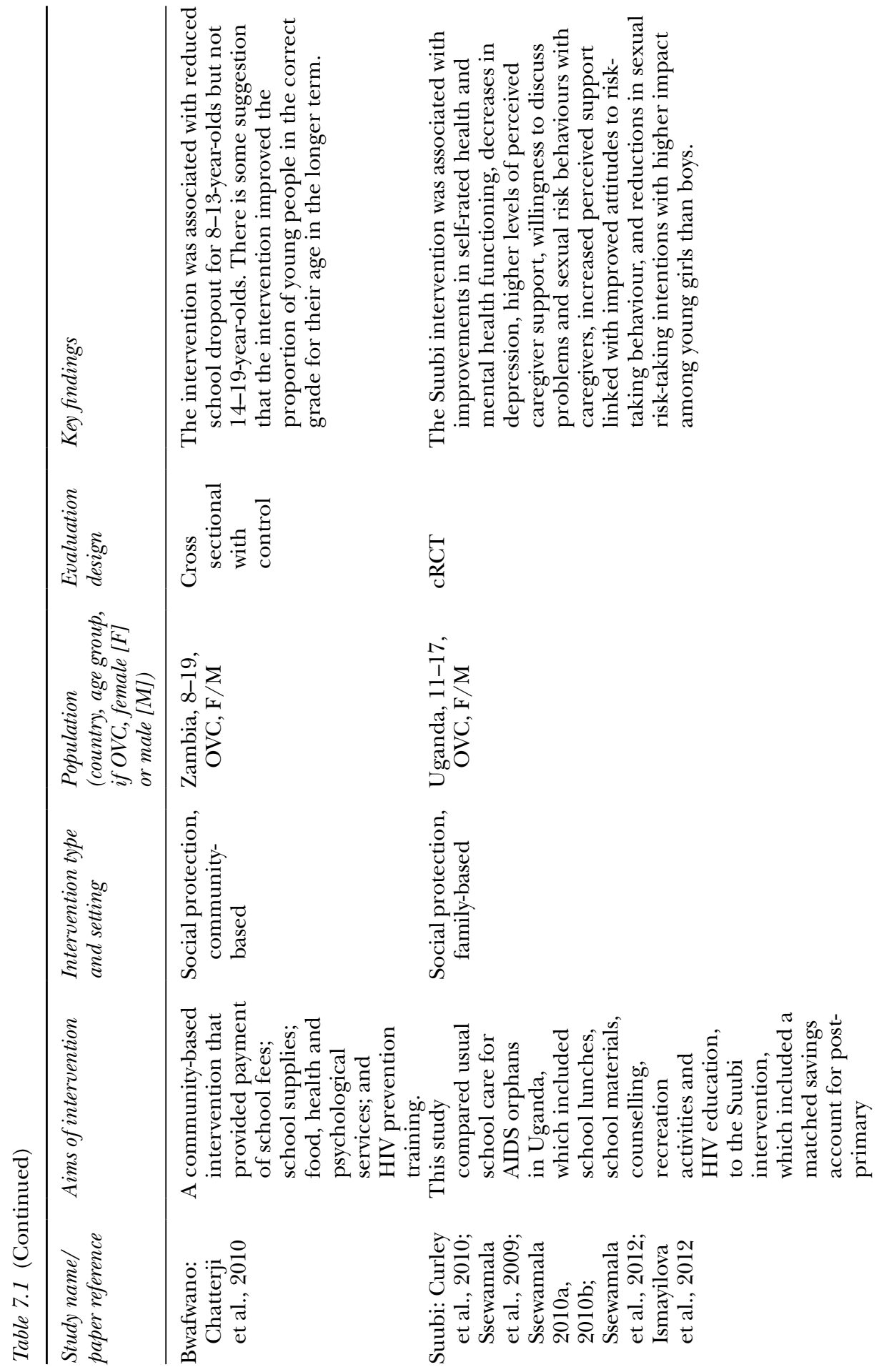




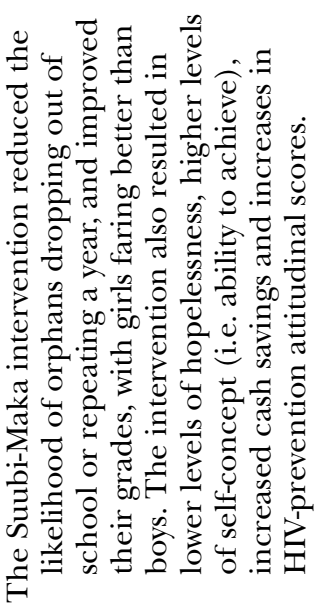

धु
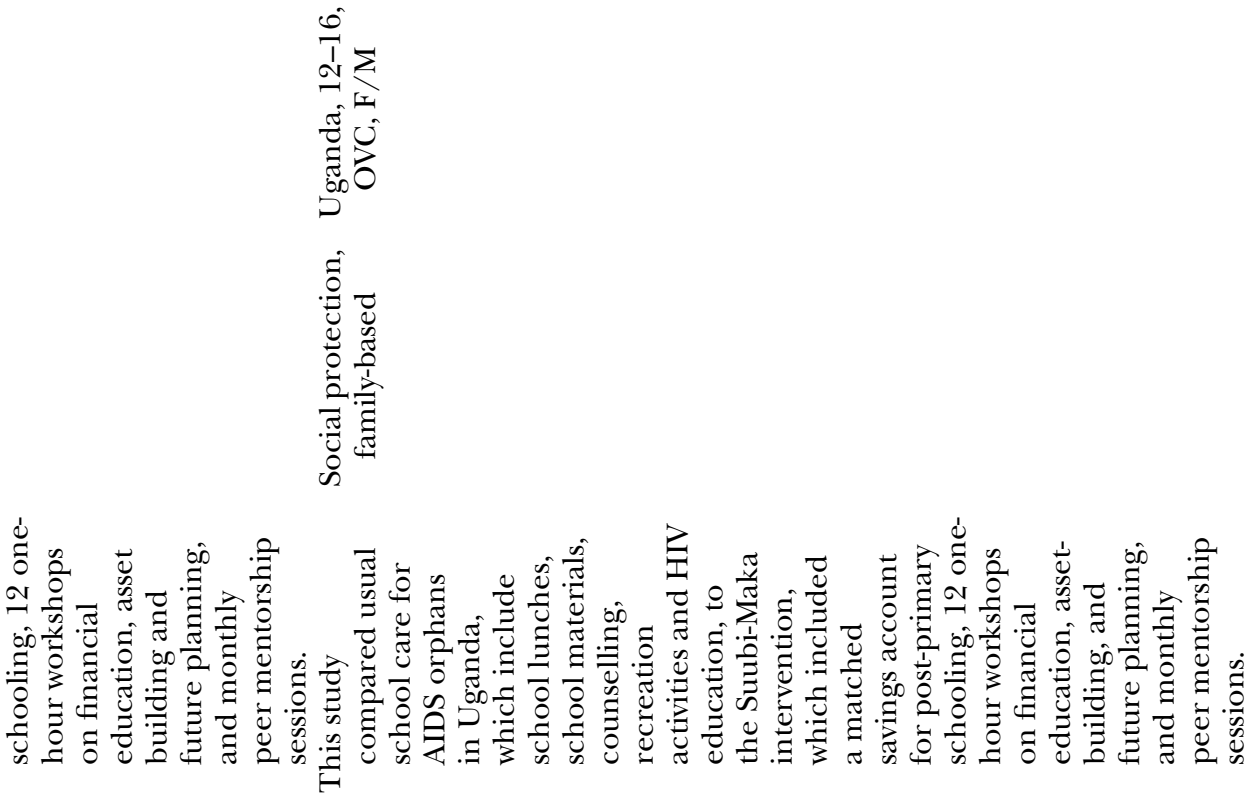

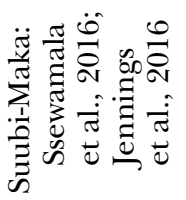




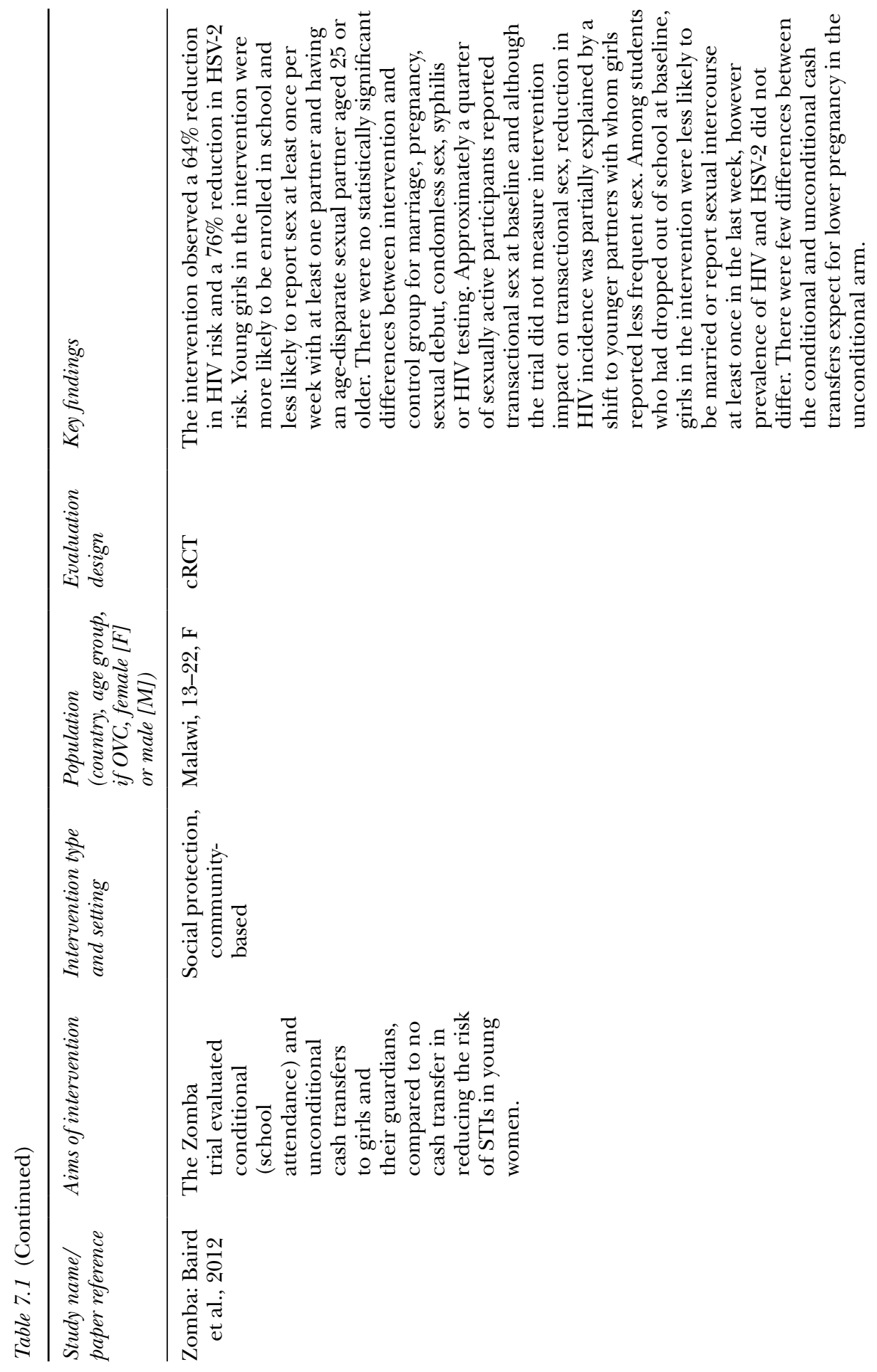




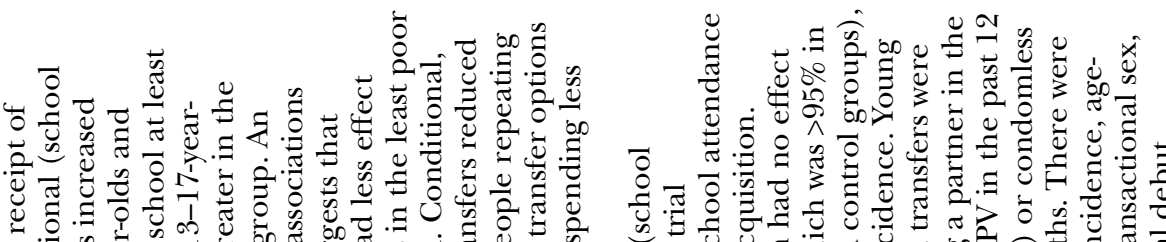

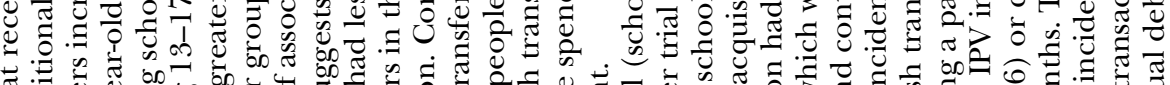

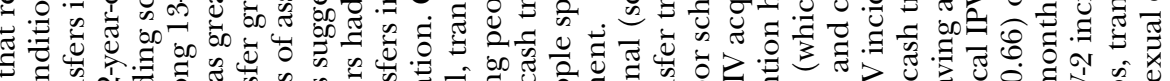

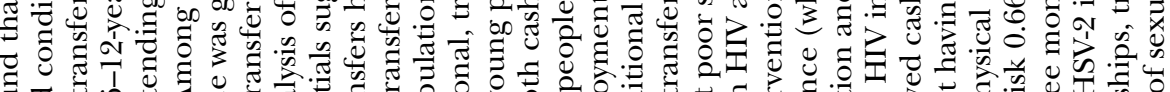

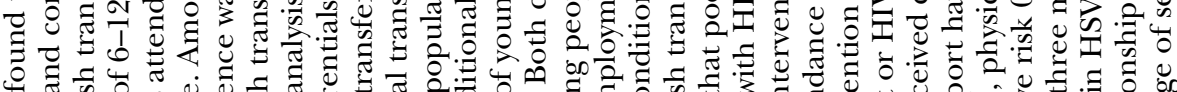

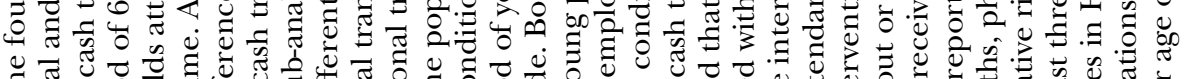

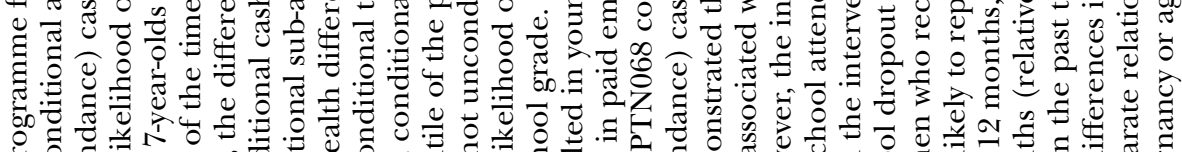
ơ

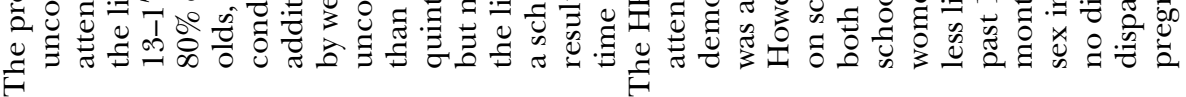

艺

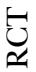

要

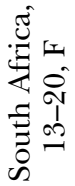

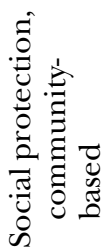

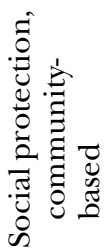

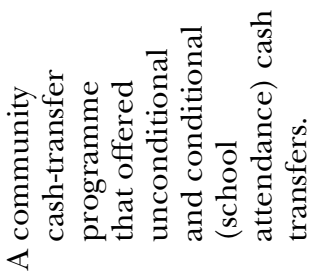

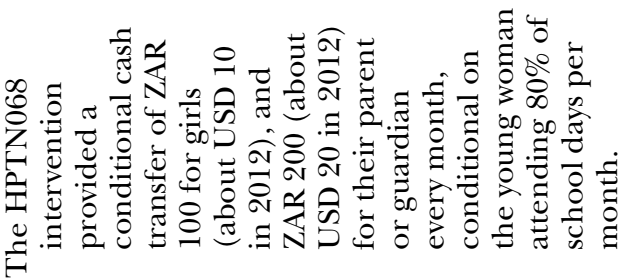

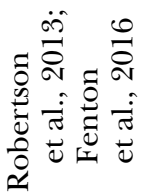

审 
142 Mitzy Gafos et al.

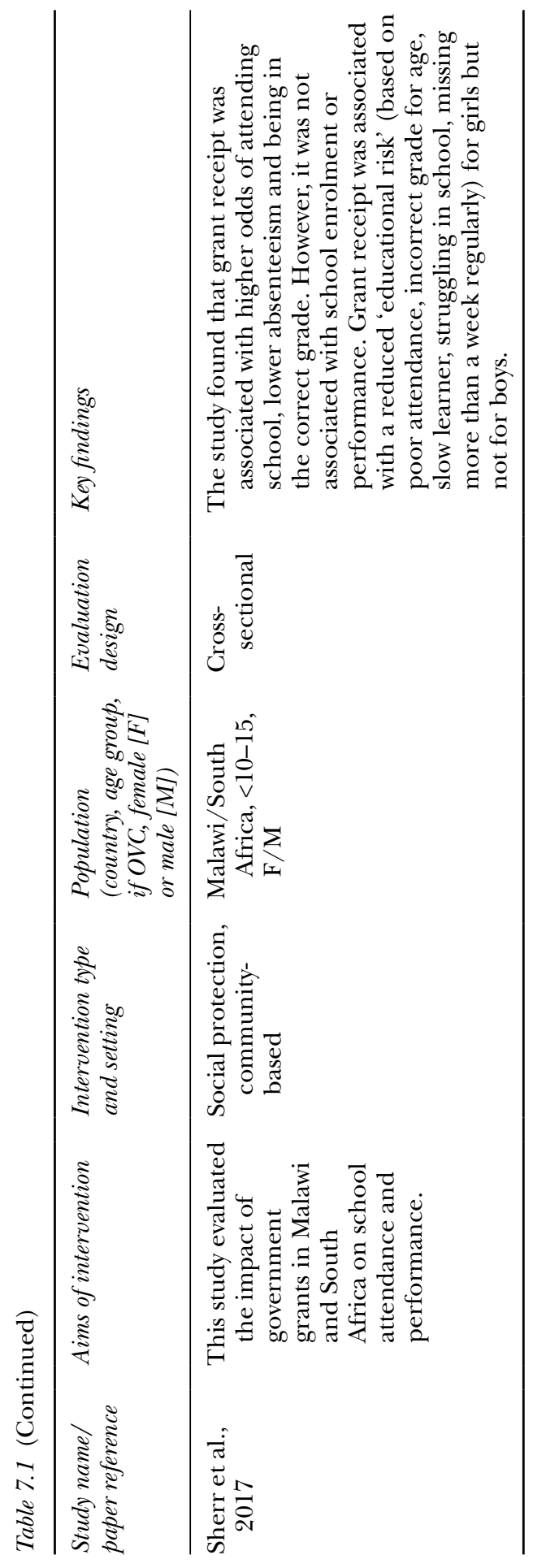




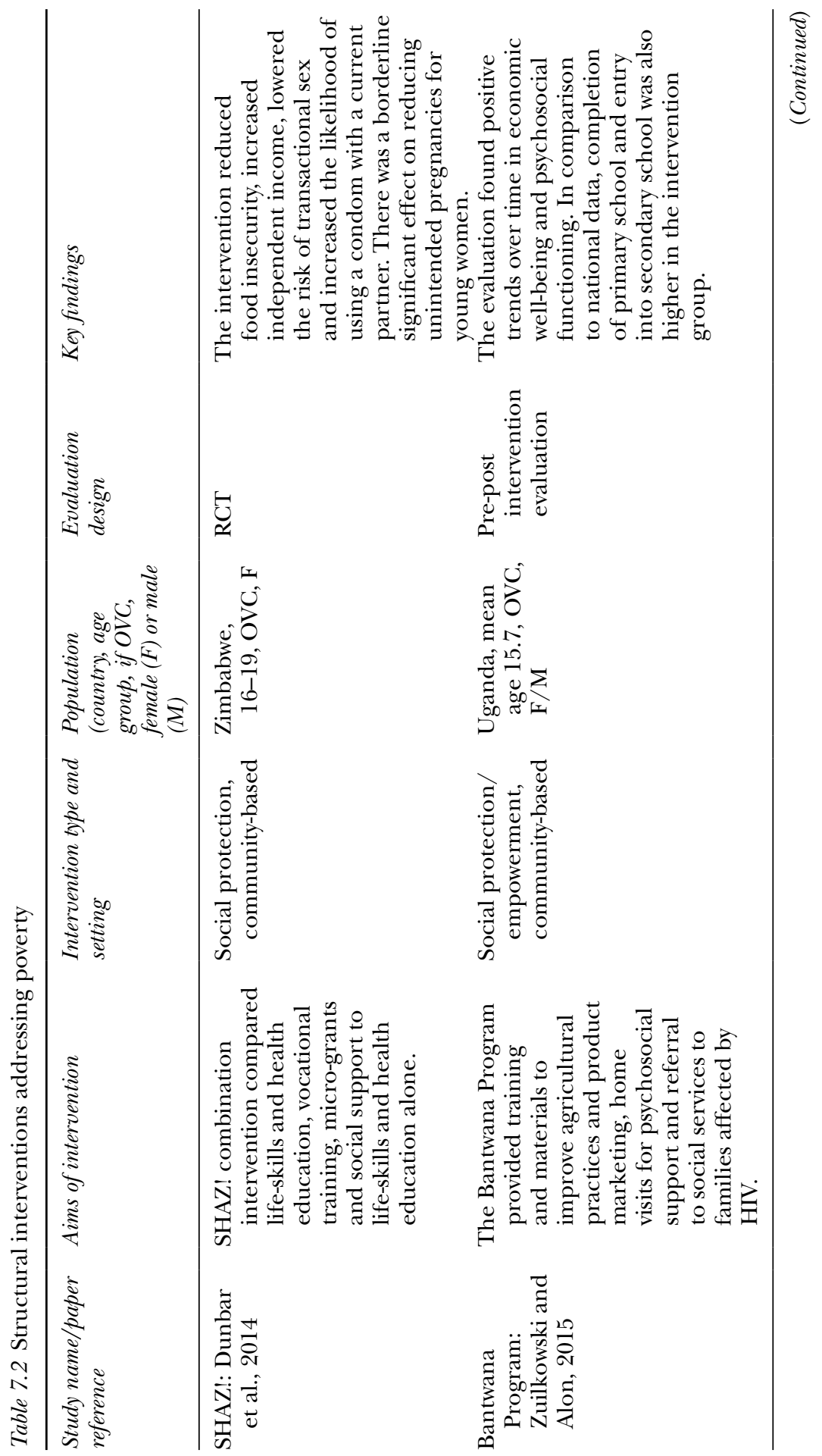




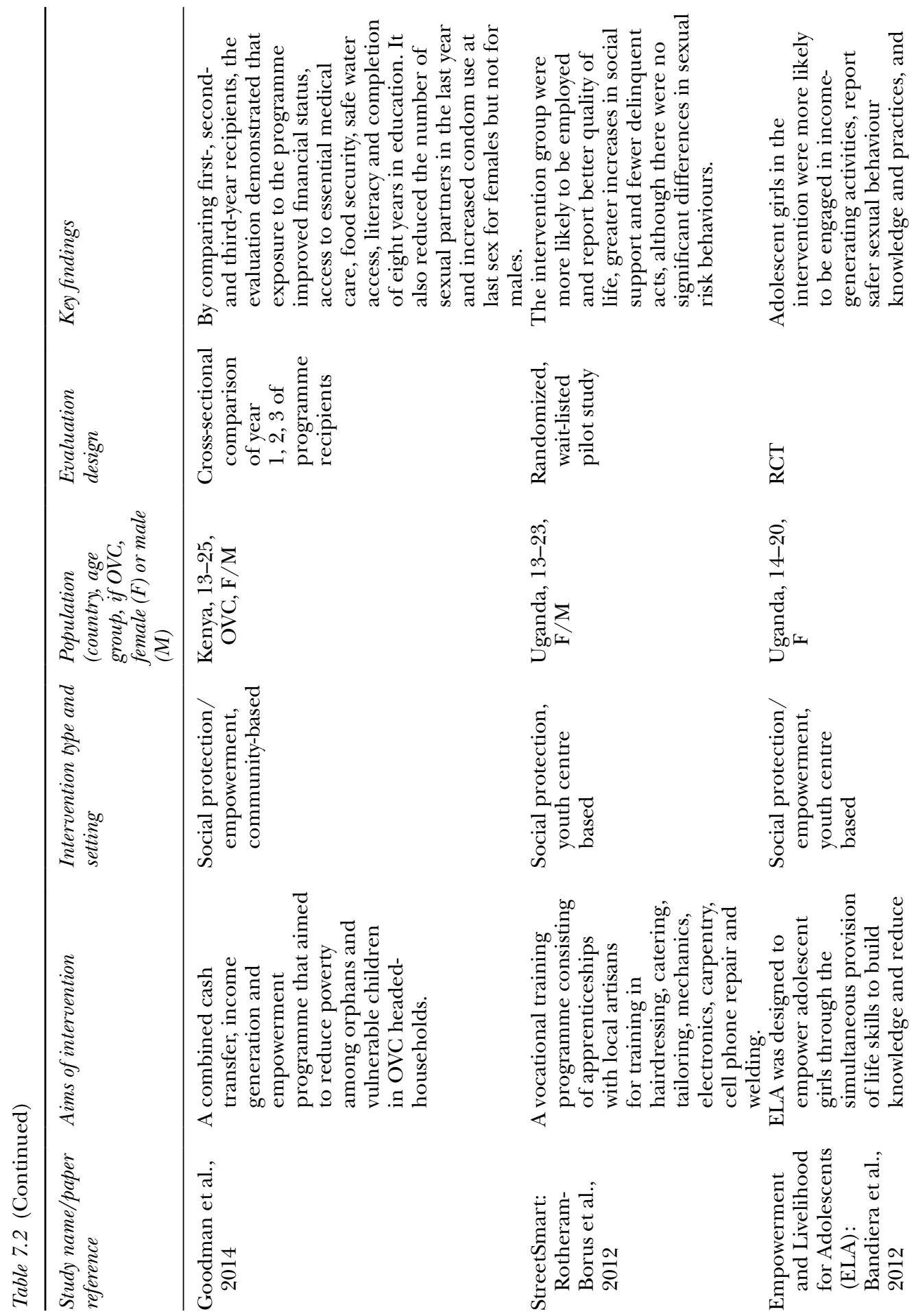




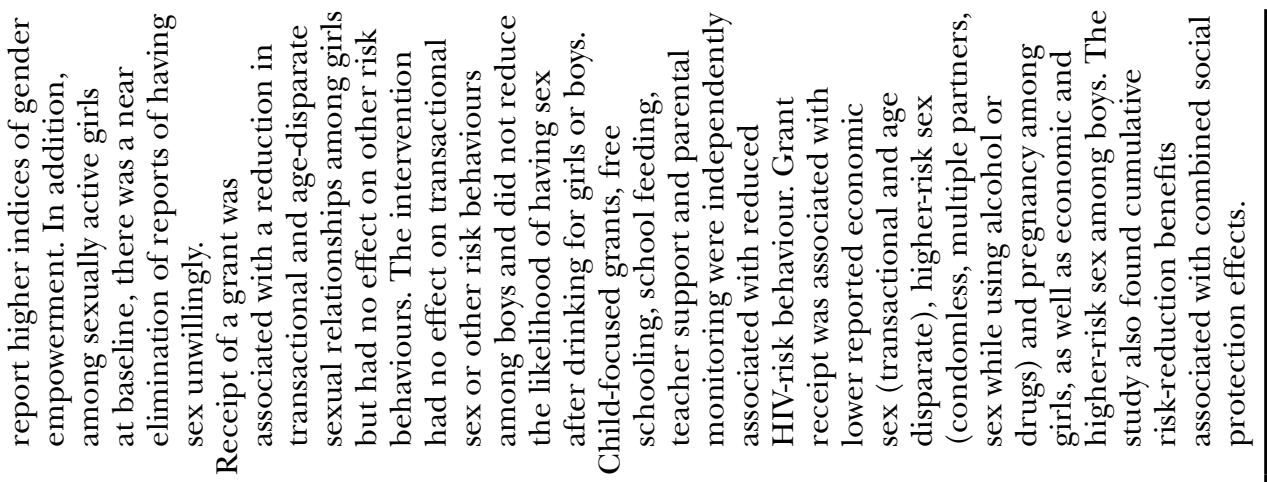

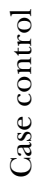

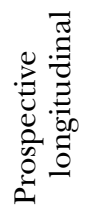

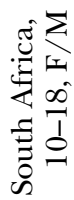

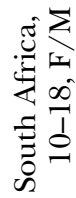
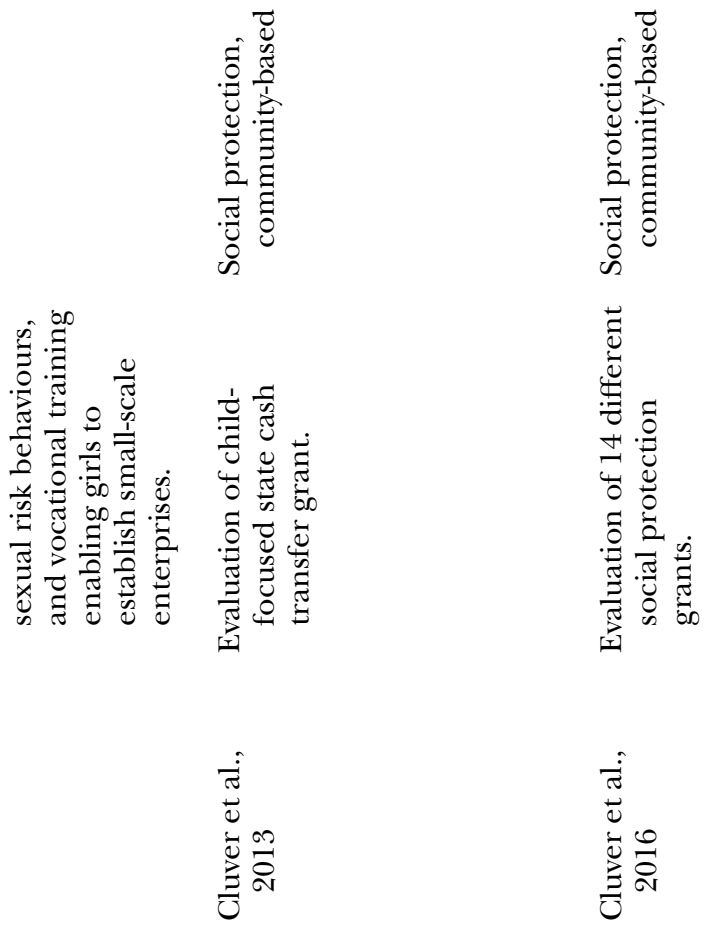


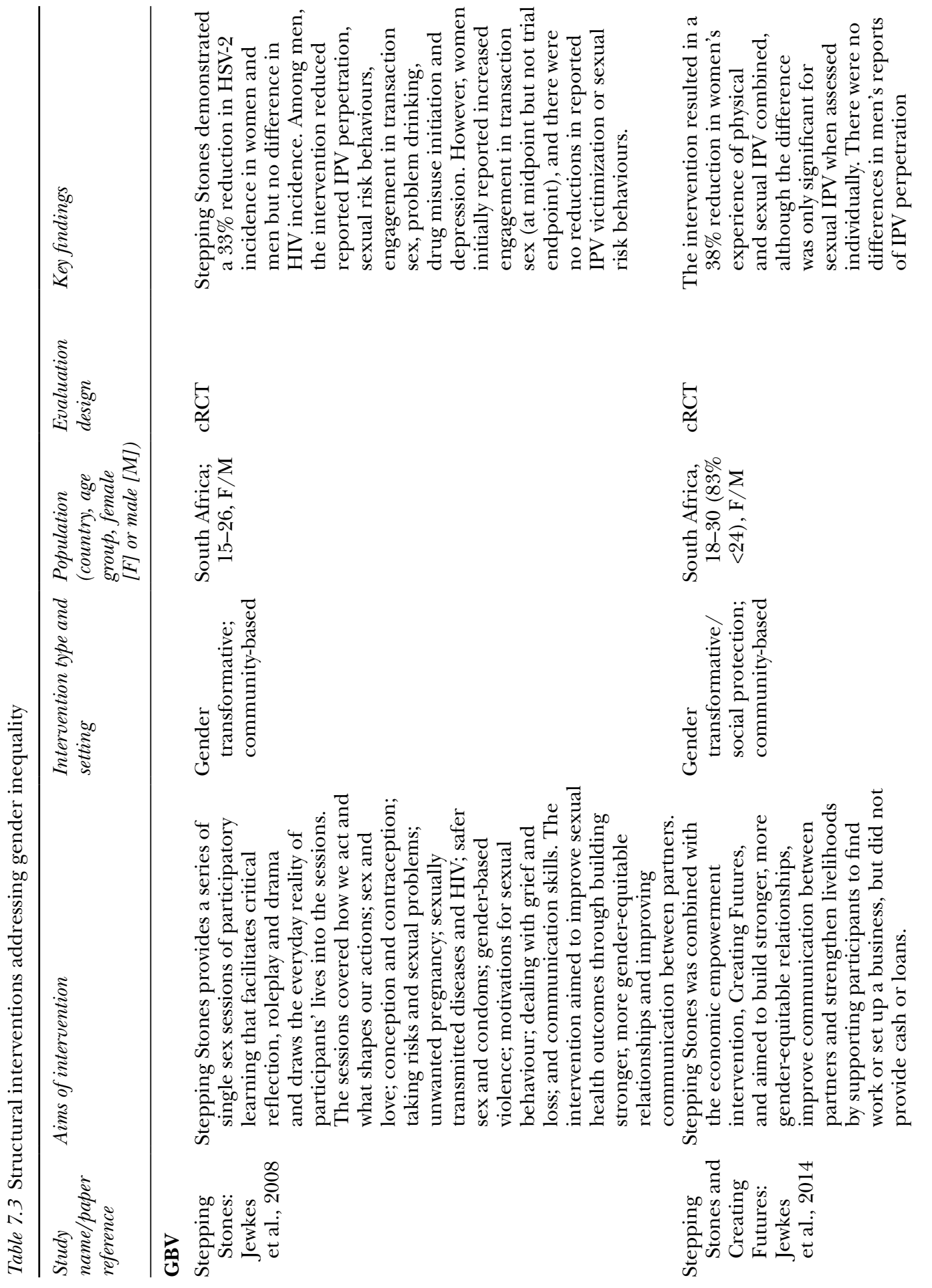



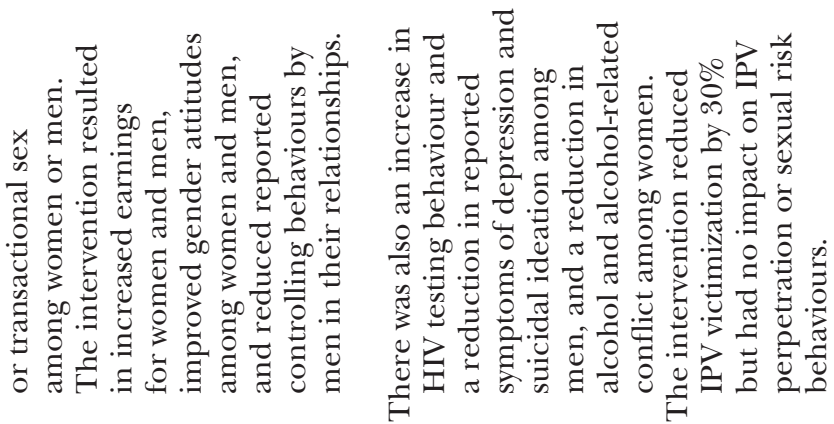

$\frac{1}{0}$
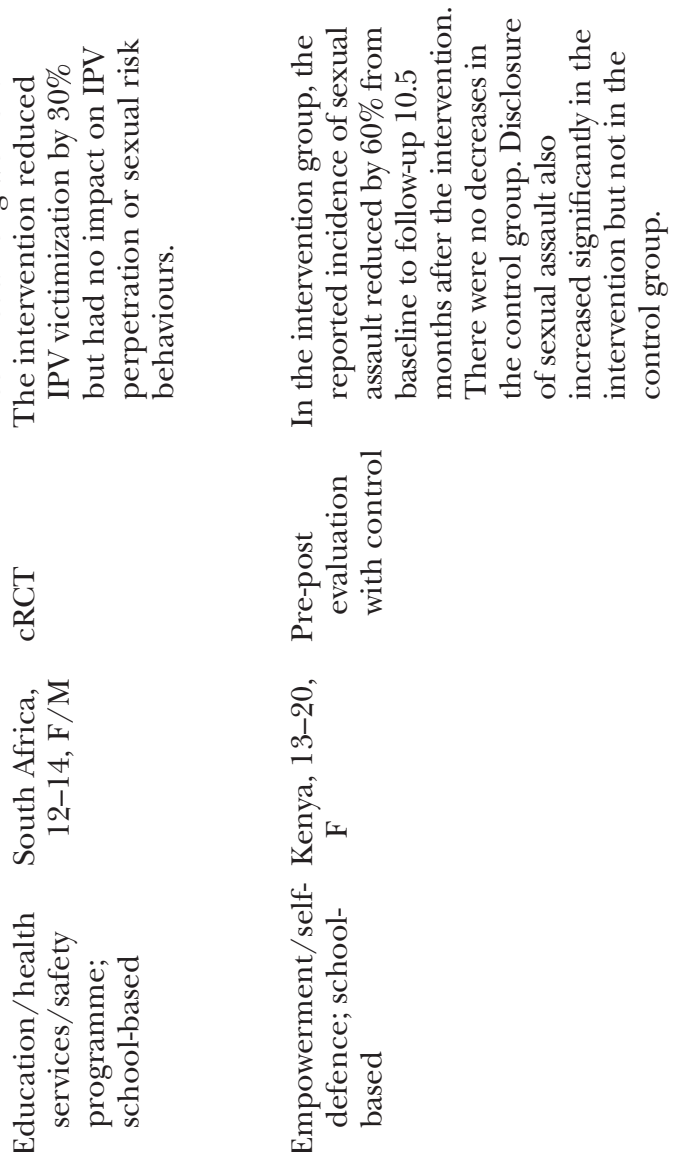

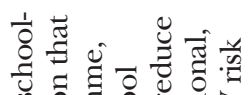

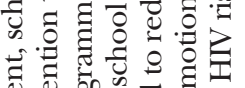

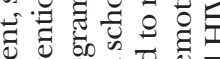

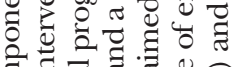

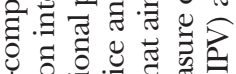

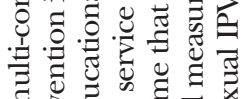

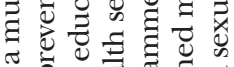

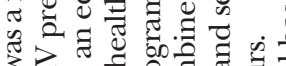

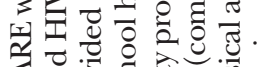

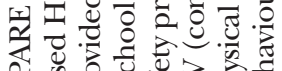

당

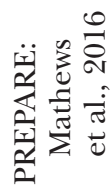

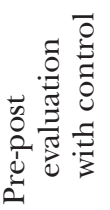

0
0
1
0
0
0
0
0
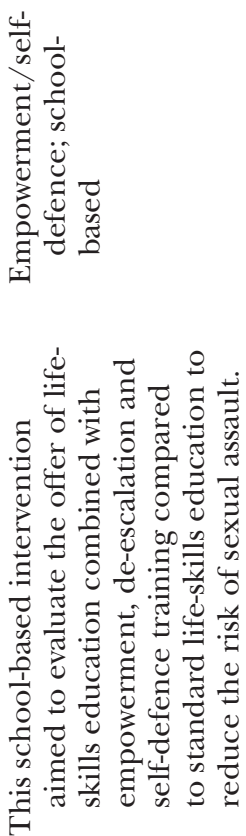

离 


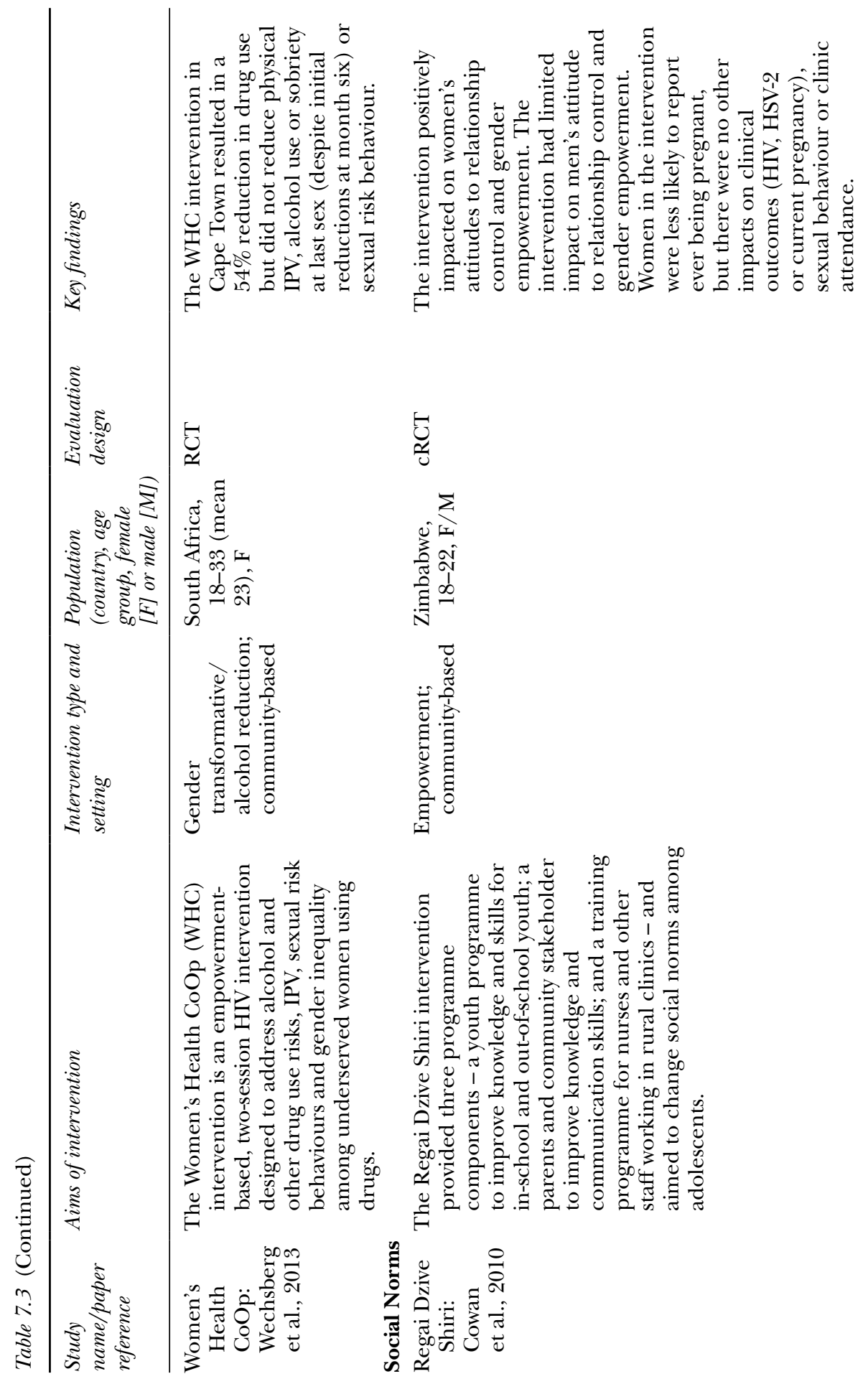




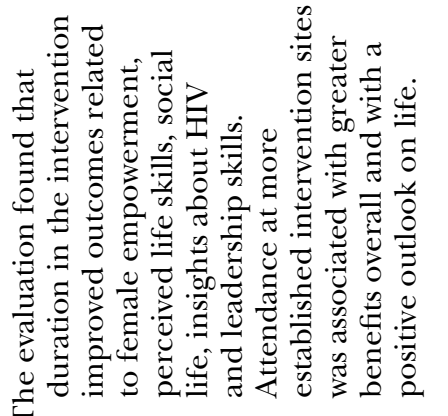

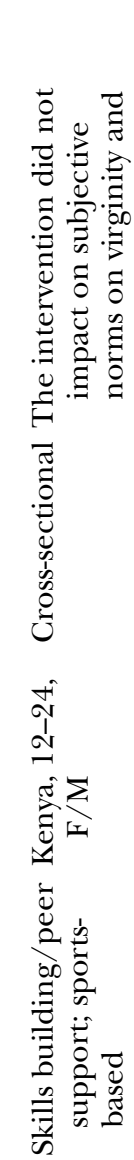

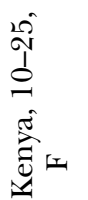

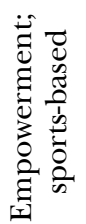

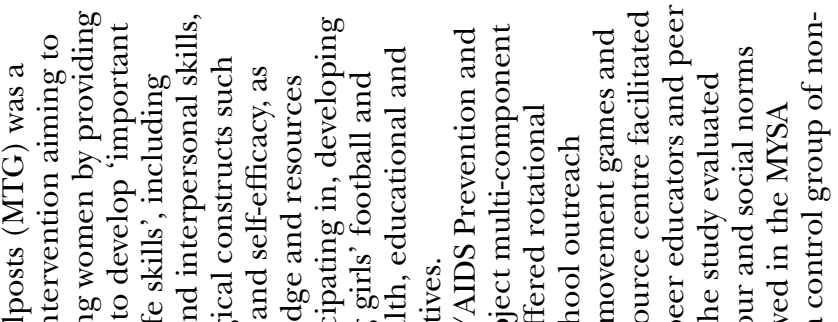

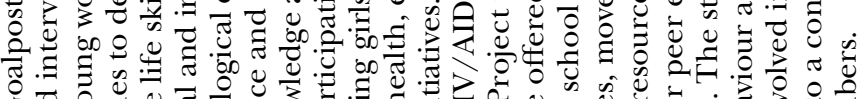
๖

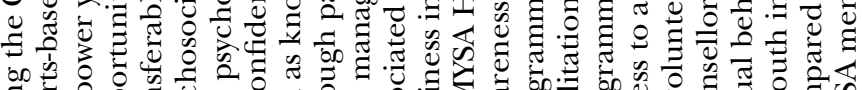

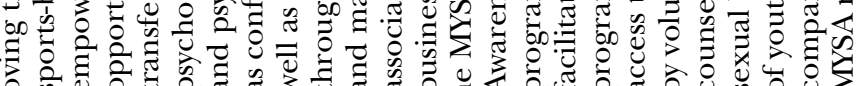

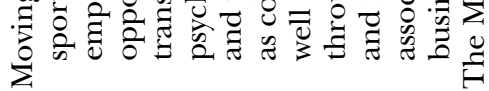
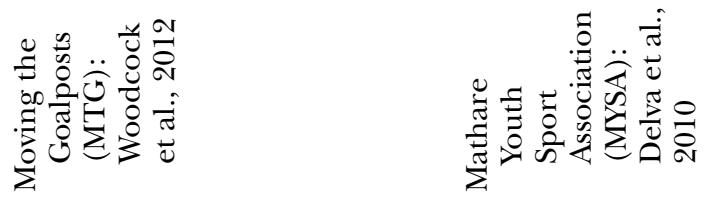


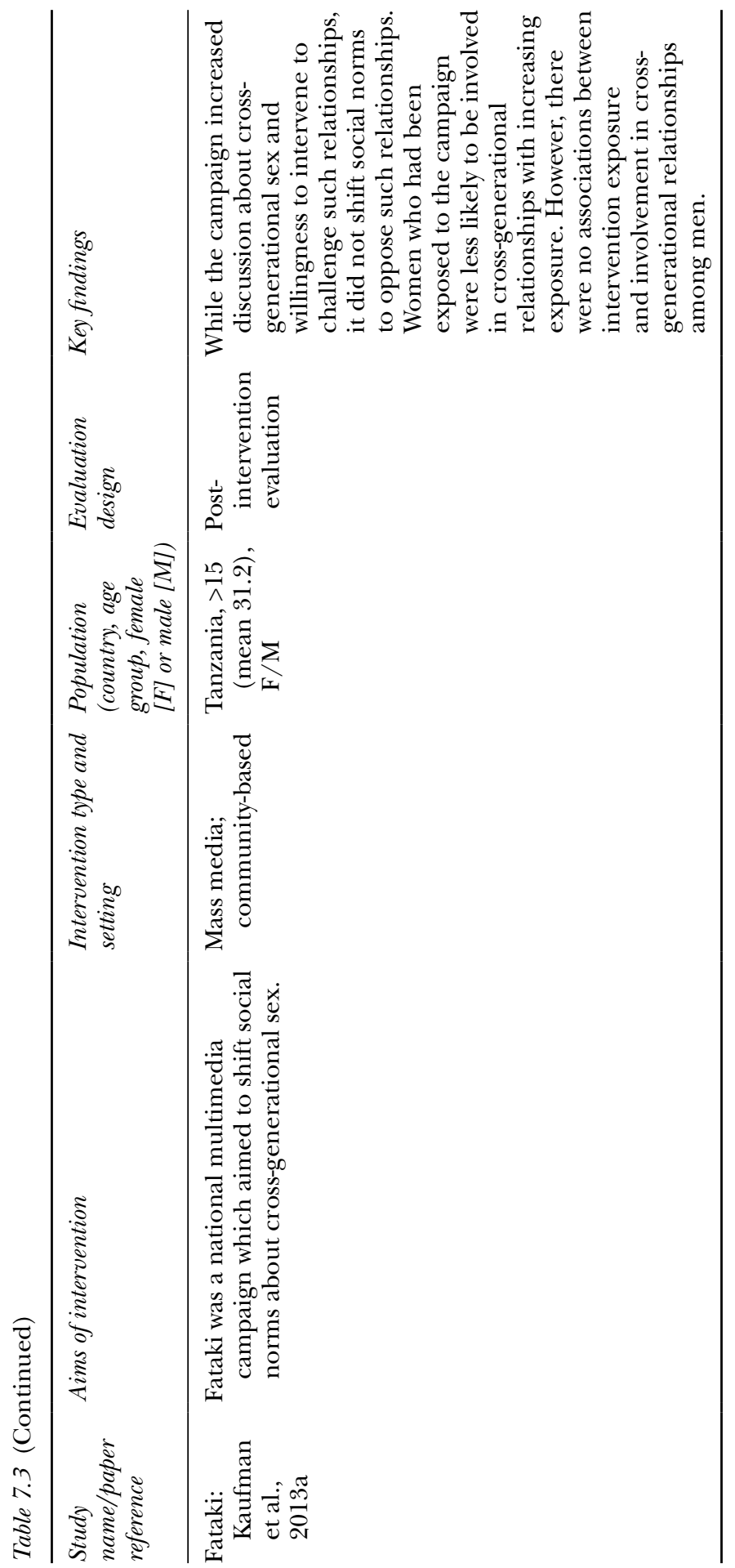




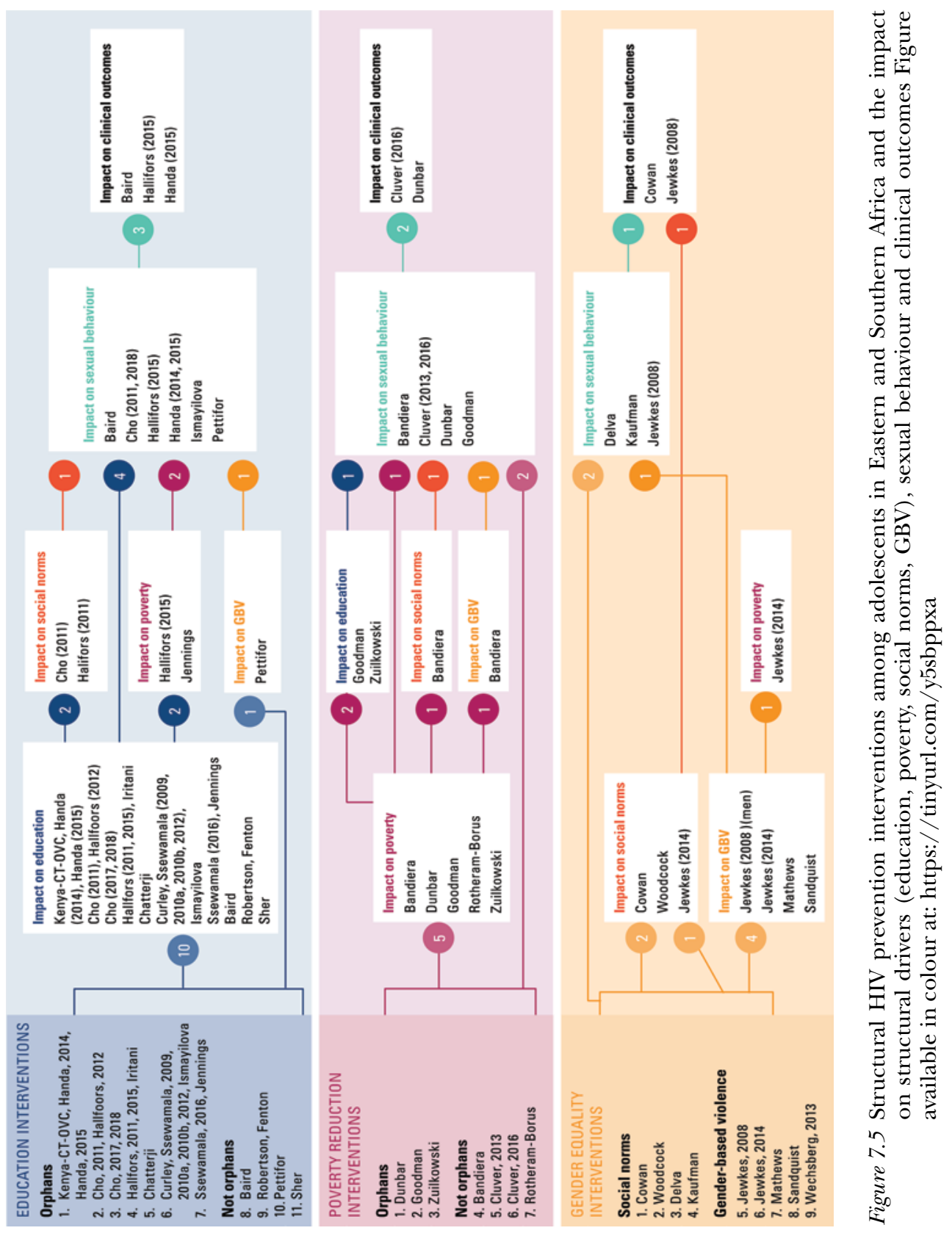


One intervention included young women only; the rest also included young men.

One study evaluated the impact of an unconditional cash transfer to caregivers of OVC in Kenya, and four evaluated broader social protection packages including paying tuition and exam fees, providing school uniforms and supplies, and providing support from community outreach workers to monitor and help avoid school absenteeism in Kenya, Zambia and Zimbabwe. The remaining two compared usual school care for AIDS orphans in Uganda, which includes school lunches, school materials, counselling, recreation activities and HIV education, with the Suubi (which means 'hope') or Suubi-Maka (which means 'hope for families') interventions, which included a matched savings account for post-primary schooling, 12 onehour workshops on financial education, asset-building, future planning and monthly peer mentorship sessions.

All the interventions demonstrated positive impacts in terms of reducing school dropout. However, the intervention in Zambia reduced school dropout for 8-13-year-olds but not 14-19-year-olds (Chatterji et al., 2010). Analysis of an intervention among young girls in Zimbabwe found that the offer of school fees during the transition from primary to secondary school appeared to have the greatest impact on school retention (Iritani et al., 2016). Two studies reported on the maintenance of intervention effects. An evaluation of the Kenyan intervention two years after the programme ended demonstrated that the effect on school dropout had dissipated (Hallfors et al., 2012). However, an evaluation of the Zimbabwean pilot intervention at the five-year follow-up showed that the intervention group were more likely to still be in school and had achieved almost one additional year of schooling (Hallfors et al., 2015).

Only four interventions reported on educational attainment. One intervention resulted in more age-appropriate progression, higher average grade level in school, higher matriculation into secondary school and increased expectations of completing college/university, but no impact on primary and secondary school test scores (Cho et al., 2017). In the intervention that reduced school dropout only for 8-13-year-olds, there was some suggestion that the intervention improved the proportion of young people in the correct grade for their age in the longer term (Chatterji et al., 2010). The Suubi and Suubi-Maka interventions were both associated with improvements in academic grades, with girls faring better than boys in Suubi-Maka (Curley et al., 2010; Ssewamala et al., 2016).

Four of the seven interventions reported sexual behaviour outcomes. All four trials demonstrated an effect on reducing the probability of early age sexual debut (Handa et al., 2014; Cho et al., 2011; Hallfors et al., 2015), and one reduced transactional sex among sexually active participants (Cho et al., 2018). However, the Kenya unconditional cash transfer programme did not have an impact on transactional sex, condom use or number of partners (Handa et al., 2014). Two interventions measured early marriage 
as an outcome, with one showing no effect (Handa et al., 2015) and the other showing a reduction in the likelihood of early marriage (Hallfors et al., 2015).

Three interventions measured clinical outcomes. The unconditional cash transfer programme in Kenya and the broader social protection programme in Zimbabwe both reported reductions in the likelihood of pregnancy (Handa et al., 2015; Hallfors et al., 2015). However, neither of the two interventions that measured an impact on HIV or HSV-2 outcomes reduced infections within the timeline of the programme, with very few HIV cases observed (Hallfors et al., 2015; Cho et al., 2018). Only the broader social protection intervention in Kenya reported on uptake of voluntary medical male circumcision (VMMC), with young men in the intervention group being twice as likely than the control group to get circumcised (Cho et al., 2018).

Five studies suggest additional benefits of the interventions. These included improving attitudes towards delaying sex and more equal gender norms (Cho et al., 2011; Hallfors et al., 2011); improved quality of life indicators, including fewer reported problems with depression/anxiety/ hopelessness; improved performance of usual activities and higher levels of confidence in the ability to achieve (Cho et al., 2018; Hallfors et al., 2015; Ssewamala et al., 2009; Ssewamala et al., 2012; Jennings et al., 2016); and improved support structures (Ismayilova et al., 2012; Cho et al., 2011), food security (Hallfors et al., 2015) and cash savings (Jennings et al., 2016).

\section{School attendance: non-OVC}

Of the remaining four interventions that aimed to improve school attendance beyond OVC, one evaluated conditional cash transfers and two evaluated conditional and unconditional cash transfer schemes in Malawi, Zimbabwe and South Africa. The conditional schemes were based on school attendance. The other study evaluated the impact of government grants in Malawi and South Africa. Two of the interventions included young women only, and the other two also included young men from younger than 10 to 22 years of age.

All but one of these interventions showed a positive impact on school attendance. Only the HPTN068 conditional cash transfer intervention in South Africa had no effect on school attendance, but attendance was $>95 \%$ in both the intervention and control groups (Pettifor et al., 2016). Of the two trials that evaluated both conditional and unconditional cash transfers, one showed little difference between the schemes on school attendance (Baird et al., 2012). However, the other found that receipt of unconditional and conditional cash transfers increased the likelihood of 6-12-yearolds and 13-17-year-olds attending school at least $80 \%$ of the time, but the difference was greater in the conditional cash transfer group among 


\section{Mitzy Gafos et al.}

13-17-year-olds (Robertson et al., 2013). An additional sub-analysis of this intervention by wealth differentials suggests that unconditional transfers had less effect than conditional transfers in the least poor quintile of the population. In the same intervention, conditional (but not unconditional) transfers reduced the likelihood of young people repeating a school grade, and both cash transfer options resulted in young girls and boys spending less time in paid employment (Fenton et al., 2016). Evaluation of the impact of government grants in Malawi and South Africa found that grant receipt was associated with higher odds of attending school, lower absenteeism and being in the correct grade. However, it was not associated with school enrolment or performance. Grant receipt was associated with a reduced 'educational risk' (based on poor attendance, incorrect grade for age, slow learner, struggling in school, missing more than a week regularly) for girls but not for boys (Sherr et al., 2017).

Only two interventions reported an impact on sexual risk behaviours, both of which only included young women. Recipients of the Zomba intervention were less likely to report regular sex and having an age-disparate sexual partner aged 25 or older. However, there were no statistically significant differences between intervention and control group for sexual debut, condomless sex or early marriage. Among students who had dropped out of school at baseline, girls in the intervention were less likely to be married or report regular sex (Baird et al., 2012). In HPTN068, young women who received cash transfers were less likely to report having a partner in the last year or condomless sex in the last quarter. These impacts were likely due to the economic impact of the transfer given that there were no impacts on school attendance. There were no differences in age of sexual debut, agedisparate relationships or transactional sex (Pettifor et al., 2016).

The same two interventions measured clinical outcomes. The Zomba intervention resulted in a reduction in HIV, HSV-2 and pregnancy (Baird et al., 2012). The reduction in HIV incidence was partially explained by a shift to younger partners with whom girls reported less frequent sex. There were few differences between the conditional and unconditional cash transfers, expect for lower pregnancy in the unconditional arm (Baird et al., 2012). The HPTN068 trial demonstrated that poor school attendance was associated with HIV acquisition, but given that it did not influence school attendance, it is not surprising that it did not impact on HIV, HSV-2 or pregnancy (Pettifor et al., 2016). Few of these studies reported additional outcomes, but HPTN068 reported a 34\% reduction in physical IPV (Pettifor et al., 2016).

\section{Poverty reduction}

We identified seven interventions that aimed to alleviate the impact of poverty: two on female and male OVC and one on only female OVC, aged 13-25 in Kenya, Zimbabwe and Uganda. The other four interventions were 
among 10-23-year-olds, one just with young women and the rest including young men, in South Africa and Uganda. Importantly, all interventions were community based and included young people out of school.

Among OVC, the SHAZ! intervention added vocational training, microgrants and social support to the life-skills and health education curriculum in schools in Zimbabwe (Dunbar et al., 2014). The Bantwana Program in Uganda provided OVC households with training and materials to improve agricultural practices and product marketing, home visits for psychosocial support and referrals to social services (Zuilkowski and Alon, 2015). The Kenyan intervention combined cash transfers, income generation and empowerment training (Goodman et al., 2014). Among non-OVC groups, the StreetSmart intervention provided vocational training to young women and men living in slums in Kampala in a wait-listed trial design (RotheramBorus et al., 2012). The Empowerment and Livelihood for Adolescents (ELA) programme in Uganda offered young girls life-skills and vocational training to support the establishment of small-scale enterprises (Bandiera et al., 2012). The final two studies evaluated the impact of state grants, both conditional and unconditional, among young women and men in South Africa on sexual risk behaviours, but did not report socio-economic outcomes (Cluver et al., 2013; Cluver et al., 2016).

All five interventions that aimed to improve socio-economic outcomes had a positive effect. Among OVC, this included reduced food insecurity, improved financial status and economic well-being, increased independent income and improved access to essential medical care and safe water (Dunbar et al., 2014; Zuilkowski and Alon, 2015; Goodman et al., 2014). Among non-OVC, there was increased likelihood of being employed (RotheramBorus et al., 2012) and of young girls being engaged in income-generating activities (Bandiera et al., 2012).

All but one of the seven interventions reported sexual behaviour outcomes. Among OVC, this included a reduction in risk of transactional sex and increased likelihood of using a condom with a current partner among young women in Zimbabwe (Dunbar et al., 2014) and a reduction in number of sexual partners in the last year and increased condom use at last sex for young women but not for young men in Kenya (Goodman et al., 2014). Among non-OVC, there were reports of safer sexual behaviour among young women in the ELA intervention in Uganda (Bandiera et al., 2012) but no difference in sexual risk behaviours among young women and men in the StreetSmart intervention, also in Uganda (Rotheram-Borus et al., 2012). Evaluation of the impact of child grants on young people in South Africa found the receipt of a grant was associated with a reduction in transactional and age-disparate sexual relationships among girls but had no effect on other risk behaviours for girls or on any risk behaviours among boys (Cluver et al., 2013). Evaluation of 14 different social protection grants in South Africa found that child-focused grants, free schooling, school feeding, teacher support and parental monitoring were independently 
associated with reduced HIV-risk behaviours, including reductions in economic sex (transactional and age disparate) and higher risk sex (condomless, multiple partners, sex while using alcohol or drugs) in young girls and boys. The study also found cumulative risk-reduction benefits associated with combined social protection grants (Cluver et al., 2016).

Only two studies reported on clinical outcomes. The SHAZ! intervention observed a borderline significant effect on reducing unintended pregnancies among young women (Dunbar et al., 2014), and grant receipt reduced pregnancy among girls in South Africa (Cluver et al., 2016). Other reported benefits among OVC included improvements in psychosocial functioning and higher completion of primary school and entry into secondary school (when compared to national data) (Zuilkowski and Alon, 2015), and higher literacy and completion of eight years in education (Goodman et al., 2014). Among non-OVC, other benefits included better quality of life, increased social support and fewer delinquent acts among StreetSmart participants (Rotheram-Borus et al., 2012), and higher indices of gender empowerment and near elimination of reports of having sex unwillingly among sexually active young women (Bandiera et al., 2012).

\section{Addressing gender inequality to reduce the risk of HIV}

We identified nine interventions that aimed to address gender inequalities (Table 7.3). Five aimed to address gender-based violence, although only three exclusively included young people aged 12-26 in Kenya and South Africa. Two additional interventions in South Africa included cohorts of women aged 18-30, but with 83\% below 24 years of age, and aged 18-33 but with a mean age of 23 , so we are including them here. In addition, four interventions aimed to shift social norms: one was exclusively for young women and two included young women and men, ranging in age from 10 to 25 years old in Kenya and Zimbabwe. A mass media campaign in Tanzania included young people and adults, and although the evaluation included respondents of a median age of 31 , we report it here as a rare example of an intervention that aimed to shift national social norms regarding young peoples' sexual partnerships.

\section{Gender-based violence}

Four interventions that aimed to address gender-based violence focus on IPV and one on sexual assault. Three of the interventions were community based and two were school based. Four included gender-transformative components, one in combination with social protection components. The other was a skills-based training intervention.

Stepping Stones is an HIV prevention intervention in South Africa among young women and men that aims to improve sexual health outcomes through building stronger, more gender-equitable relationships 
and improving communication between partners (Jewkes et al., 2008). In a subsequent community-based intervention also in South Africa, Stepping Stones was combined with Creating Futures, an economic empowerment programme to strengthen livelihoods by supporting participants to find work or set up a business, but did not provide cash or loans (Jewkes et al., 2014). A school-based intervention in Kenya offered empowerment, de-escalation and self-defence training to adolescent girls in addition to standard life-skills education to reduce the risk of sexual assault (Sarnquist et al., 2014). PREPARE was a multi-component, school-based HIV prevention intervention including after-school educational sessions, school health services and a school-based safety programme designed to reduce IPV and HIV risk behaviours (Mathews et al., 2016). Finally, the Women's Health CoOp (WHC) intervention in Cape Town enrolled women reporting drug or alcohol use in an empowerment and skills-building programme (Wechsberg et al., 2013).

Four of the five interventions demonstrated positive impacts on IPV victimization, perpetration or sexual assault. Stepping Stones and Creating Futures resulted in a 38\% reduction in women's experience of physical and sexual IPV combined, although the difference was only significant for sexual IPV when assessed individually. There were no differences in men's reports of IPV perpetration (Jewkes et al., 2014). PREPARE reduced IPV victimization (composite of emotional, physical, sexual) by $30 \%$ but had no impact on IPV perpetration (Mathews et al., 2016). Stepping Stones did not reduce IPV victimization (physical and sexual) among young women but did reduce reported IPV perpetration (physical and sexual) among men (Jewkes et al., 2008). The one intervention among substance-using women in Cape Town showed no impact on physical IPV (Wechsberg et al., 2013). In the Kenya study, there was a $60 \%$ reduction in the reported incidence of sexual assault between baseline and follow-up, 10.5 months after the intervention. There were no decreases in the control group. Disclosure of sexual assault also increased significantly in the intervention but not in the control group (Sarnquist et al., 2014).

Four studies reported sexual behaviour outcomes. Among men, Stepping Stones reduced sexual risk behaviours, including engagement in transactional sex. However, women initially reported increased engagement in transactional sex (at midpoint but not trial endpoint) and no reductions in other sexual risk behaviours (Jewkes et al., 2008). There were no impacts on sexual risk behaviours including transactional sex in the other interventions (Jewkes et al., 2014; Mathews et al., 2016; Wechsberg et al., 2013). Only Stepping Stones reported a clinical outcome, demonstrating a $33 \%$ reduction in HSV-2 incidence in women and men but no difference in HIV incidence (Jewkes et al., 2008).

Additional benefits included increased earnings for women and men, improved gender norms in terms of attitudes among women and men and reduced reported controlling behaviours by men in their relationships, an 
increase in HIV testing behaviour and a reduction in reported symptoms of depression and suicidal ideation among men, and a reduction in alcohol and alcohol-related conflict among women in Stepping Stones and Creating Futures (Jewkes et al., 2014). Stepping Stones resulted in a reduction in problem drinking (AUDIT score), drug misuse initiation and depression among men (Jewkes et al., 2008). The WHC intervention in Cape Town reduced drug use but did not reduce alcohol use or sobriety at last sex (despite initial reductions at month six) (Wechsberg et al., 2013).

\section{Social norms}

In addition to the GBV intervention that influenced social norms, mentioned earlier (Jewkes et al., 2014), four community-based interventions primarily aimed to address social norms. The Regai Dzive Shiri programme in Zimbabwe for in-school and out-of-school youth included peer education and participatory learning, community-based sessions for parents and community stakeholders, and training for nurses and other staff in rural clinics. It aimed to change social norms about sex among adolescents to support individual behaviour change (Cowan et al., 2010). There were two sports-based interventions in Kenya: the Moving the Goalposts (MTG) football programme aiming to empower young women (Woodcock et al., 2012) and the Mathare Youth Sport Association (MYSA) with adolescent girls and boys, which evaluated the impact of participation on social norms around gender and sexual behaviour (Delva et al., 2010). Finally, Fataki was a national multimedia campaign in Tanzania to address social norms relating to cross-generational sex (CGS) by mobilizing communities to intervene in CGS relationships. The evaluation was conducted with young people and adults age 15 or older, with a mean participant age of 31 (Kaufman et al., 2013a).

Two of the interventions demonstrated shifts in social norms. Regai Dzive Shiri positively affected young women's attitudes to relationship control and gender empowerment but had limited impact among young men (Cowan et al., 2010). The MTG evaluation found that duration in the intervention improved outcomes related to female empowerment (equal educational opportunities and playing sport during menses), perceived life skills, social life, insights about HIV, and leadership skills. Attendance at more established intervention sites was associated with greater benefits overall and with a positive outlook on life (Woodcock et al., 2012). Youth involved in the MYSA, compared to youth from youth clubs, schools and social organizations in the same areas, did not differ in terms of gendered subjective norms on virginity, responsibility or fidelity; behavioural attitudes towards risk-avoiding behaviour; or behavioural intentions concerning condom use (Delva et al., 2010). The Fataki campaign increased discussion about cross-generational sex and willingness to intervene to challenge such relationships but did not shift social norms to oppose such relationships, 
although the evaluation did not report results for participants under age 24 (Kaufman et al., 2013a).

Three of the interventions reported sexual behaviour outcomes. MYSA youth were more likely to report condom use during their first and last sexual encounters, but there were no other impacts on sexual behaviour in this study (Delva et al., 2010) or in Regai Dzive Shiri (Cowan et al., 2010). Women who had been exposed to the Fataki campaign were less likely to be involved in cross-generational relationships, although there was no association between intervention exposure and involvement in crossgenerational relationships among men (Kaufman et al., 2013a). Only the Regai Dzive Shiri intervention measured clinical outcomes and found that young women in the intervention were less likely to report ever being pregnant, but there were no other impacts on HIV, HSV-2 or current pregnancy (Cowan et al., 2010).

\section{Lessons and challenges for the future}

Within the scope of this review, all but one of the structural interventions designed to improve school attendance had a positive impact on schooling. All structural interventions designed to reduce poverty had a positive impact on socio-economic outcomes. When evaluating educational attainment in the context of age-appropriate grades, the outcomes were generally positive, although there is clearly a need for additional evaluation of the impact on educational achievement, such as exam scores. While all of the seven poverty alleviation interventions included young people out of school, only one of the educational interventions included them (Baird et al., 2012). There is need for further interventions to re-engage out-ofschool youth in education, including those who have dropped out of school due to an adverse outcome such as unintended pregnancy, both to improve their educational outcomes as well as their sexual and reproductive health outcomes, including HIV risk.

The evidence for structural interventions to address gender inequalities is less consistent, with two out of four social norm interventions and one out of five GBV interventions that measured norms demonstrating a shift in norms. Given the importance of social norms in shaping perceptions of violence, it is striking that most of the GBV interventions did not measure changes in social norms. There is a need for the inclusion of social norms outcomes in more multi-component structural interventions in the future. Of five GBV interventions, there were three reported reductions in physical and/or sexual victimization, although sometimes one and not the other, and one in physical and sexual perpetration. These findings support the argument that the mechanisms of effect differ for emotional, physical, and sexual IPV victimization, and between victimization and perpetration. However, differences in studies are also likely to be due to the lack of standardized implementation methods and inconsistent measurement tools. 
There have been important developments in the establishment of standardized measurement tools of IPV which should be used in future evaluations (Heise and Hossain, 2017). There is a growing body of evidence on the use of qualitative vignettes to measure social norms, but there are still substantial challenges in designing effective quantitative measures (Cislaghi, 2017).

During screening, we identified a further five GBV interventions that included young people age 14 and older. All five reduced the risk of IPV victimization or IPV perpetration or sexual assault. However, they did not stratify results by age, so we excluded them from the review (Pronyk et al., 2006; Wagman et al., 2015; Abramsky et al., 2014; Parcesepe et al., 2016; Wechsberg et al., 2011). SASA! was a highly effective community-based intervention, and the authors confirmed that there were no differences in intervention impacts on IPV among 18-24-year-olds, although these results were not published (personal communication with Tanya Abramsky; Abramsky et al., 2014). Approximately a third of the cohorts in four of these trials were under age 24 , and stratifying the results by age could have contributed further to our understanding of how to intervene to reduce the risk of violence among young people.

In considering the breadth of the evidence on effect, there is a strong possibility of publication bias, as we did not include unpublished and other grey literature in our search and are aware of a number of relevant studies with flat or partially flat results that have thus far only been presented at conferences (Kaufman et al., 2013b; Abdool-Karim et al., 2015).

The evidence suggests that the timing of educational interventions is critical, potentially having a larger impact when intervening early to keep young people in school (Bruce, 2015). Overall, there appear to be few differences between conditional and unconditional social protection schemes, although there is a suggestion from one trial that conditional transfers may be more important for older youth from less impoverished households and have a more marked impact on educational attainment. A previous metaanalysis suggested that it is the intensity of the stipulations and monitoring of the conditionality rather than the conditionality itself that has the largest effect on school attendance (Baird et al., 2013). The relative benefit of conditional versus unconditional transfers, weighed against the complexity of large-scale implementation, is an important issue for ongoing debate. Stepping Stones and Creating Futures was the only GBV intervention to include an economic empowerment component, and resulted in positive impacts on social norms, IPV and poverty. There is increasing interest in combined gender and economic empowerment approaches.

From the available evidence, there were few differences for young women and men in terms of both education and poverty alleviation. Only two educational interventions among non-OVC youth included both young women and men, one of which suggested that the impact of unconditional grants was more pronounced for young women. However, the gender inequality interventions appear to have a more pronounced effect among young 
women, and potentially require a broader and more intensive engagement at a societal level to achieve a shift in gender norms and violence as seen in SASA! The need to engage both women and men across the generations to shift gendered perceptions remains a priority, as this also impacts on young women's access to education and economic opportunity. Certainly, a previous review of studies to prevent violence against women found greatest promise from studies that included group training for women and men, community mobilization, and combining livelihood and training interventions for women (Ellsberg et al., 2015).

There are cross-over benefits of structural interventions among youth, with two of the education interventions demonstrating positive impacts on socio-economic outcomes, one on IPV, and two on social norms; two poverty interventions impacting on educational outcomes and one on GBV and social norms; and one GBV intervention impacting on poverty (Figure 7.5). Given that singular structural drivers, such as poverty, influence the causal pathway to HIV through multiple routes, combining interventions to tackle multiple influencers of risk is vital. However, there are financial challenges to implementing multi-sectoral interventions. Zomba was the only structural intervention in this review to reduce HIV risk for young women, yet it was unlikely to be cost-effective from an HIV perspective (Baird et al., 2012). Indeed, a cost-effectiveness assessment showed that if each sector (education and health) adopted a siloed approach and assessed the value of the intervention in its sectoral silo, the intervention would not have been funded (Remme et al., 2014). By contrast, if sectors pooled their resources through a co-financing mechanism to jointly achieve their outcomes, they would be able to cover the full cost of the intervention and even spend less for the same outcomes than they would have each spent in their own sectors (Remme et al., 2012; Remme and McGuire, 2018). A pilot study in sub-Saharan Africa is currently assessing the practicalities of operationalizing the co-financing approach in governmental planning and budgeting (Vassall, 2018).

A few of the interventions suggest the importance of assessing the impact at multiple time points, ensuring sufficient time for the upstream changes to take effect, and assessing the duration of the impact. This has been highlighted in other GBV interventions as well (Wagman et al., 2015). We did not extract details on the duration of intervention or time points of evaluation from the papers reviewed. Building a body of evidence on the optimal intensity and duration for effect and timelines for evaluation will be useful going forward.

The measure of proximal risk factors and HIV infection were not inclusion criteria for this review. The self-reported nature of sexual behaviour data makes it sensitive to social desirability bias, but it still provides a useful indicator of risk behaviour change (Krumpal, 2013). Eleven out of 12 education and poverty interventions that measured sexual behaviour outcomes reported some positive effects. Of the five gender inequality interventions, 
only one had a positive impact on sexual behaviour. However, the two social norm interventions that did not impact on norms did impact on sexual behaviour, suggesting additional mechanisms of effect. The sexual behaviour results were not consistent, with some showing impact on measures such as sexual debut, transactional sex and condomless sex, but others not, and with differences by gender. The HPTN068 trial results highlight the point that cash transfers have the potential to function through multiple routes; despite having no impact on education, the intervention still resulted in positive impacts on sexual behaviour outcomes. Only three interventions assessed early marriage as an outcome, with split results. The measure of early marriage is important, as it can be a trigger for school dropout, limit young women's ability to negotiate safer sex or indicate forced child marriage, which is a risk factor for partner violence (Lloyd and Mensch, 2008; Durevall and Lindskog, 2015a).

Six of the seven educational and poverty interventions that measured clinical outcomes showed a positive effect predominantly in terms of pregnancy, while two of the gender inequality interventions showed clinical impacts on HSV-2 and ever being pregnant. Only one trial, Zomba, demonstrated a positive impact on HIV as well as HSV-2, with no impact in the other three interventions that measured HIV. Overall, there was stronger evidence for sexual behaviour and clinical impact among young women than among men. This may well reflect the differential risk for young women and men in this age group and the differential reporting bias on sexual behaviour due to social desirability (Krumpal, 2013). Although all the evidence suggests that keeping young girls in school, alleviating poverty and addressing gender inequalities will help mitigate the risk of acquiring HIV, a key challenge is establishing whether these interventions have an effect on HIV incidence. Limited evidence on the direct impact on HIV incidence is a major challenge to financing and scaling up such interventions. We need to find better ways to estimate impact over the longer term.

We conducted a comprehensive and expansive review of structural interventions among young people in ESA designed to intervene on the causal pathways to HIV infection. However, in summarizing this evidence we need to consider a number of limitations of the review. The majority of the structural interventions designed to address school attendance and poverty focused on OVC. We aimed to identify structural interventions with educational and socio-economic outcomes but which were designed to intervene on the pathway to HIV. It is possible that this search strategy emphasized the identification of interventions with OVC from households affected by HIV and failed to identify other educational and socio-economic structural interventions that may also have been relevant. There were surprisingly few interventions among young people addressing gender inequalities and, although expert review by authors supports the findings, there is a chance that their absence is a manifestation of our search strategy, especially our reliance only on the published literature. It is also noteworthy that the 
studies included in the review were all concentrated in only seven countries in ESA: Kenya, Malawi, South Africa, Tanzania, Uganda, Zambia and Zimbabwe. From experience, we know that the majority of HIV prevention research is taking place in these countries, although it is also likely that our focus on English language literature restricted evidence from other countries in the region.

\section{Recommendations and next steps}

A growing body of evidence points to the benefits of structural interventions to improve livelihood and gender equality for young people in ESA. To build on this evidence base, it will be useful to have consistent and multi-sectoral measures of effect. School attendance is a clear outcome measure, but it would be helpful to also assess a broader range of educational achievement and socio-economic indices consistently. Measures for IPV are now well defined, but there is a need for reliable tools to measure social norm change. Similarly, using consistent measures of proximal determinants would aid comparison. Recent clarifications have been made to the definition and validation of measurement tools for transactional sex (Stoebenau et al., 2016; Wamoyi et al., 2016; Wamoyi et al., 2017; UNAIDS/ STRIVE, 2018). Looking forward, we have to consider the best way to capture measures of 'protected' versus 'unprotected' sex beyond just condom use, as the availability of oral pre-exposure prophylaxis increases and the benefits of universal test and treat and VMMC are realized. In the context of expanded prevention options, it is also critical to pay attention to structural drivers that serve as barriers to prevention services, such as stigma restricting access to comprehensive sexual and reproductive health services for young people (Krishnaratne et al., 2016; Stangl, in press; Stangl et al., 2017; Stangl and Sievwright, 2016; Stangl et al., 2013; Delany-Moretlwe, 2018). The challenges of measuring an impact on HIV incidence within short time frames are clear; it would therefore be useful to collect other indices of exposure including pregnancy, HSV-2 and other relevant sexually transmitted infections (STIs) such as syphilis and chlamydia (Pinkerton et al., 2002).

While the evidence base for structural interventions is strong, the pathways of impact are not consistent. Few papers included the theory of change that underpinned the design of the intervention. It would be useful to define clearly the underlying theory of change in each intervention in order to evaluate the mechanisms of effect for individual and combined interventional components. Similarly, definitions and comparisons of intervention duration, time to impact and measures of maintenance of impact would all enhance our understanding of the value, cost-effectiveness and scalability of interventions. Differences in age groups should also be investigated (Kinghorn et al., 2018). This is as true of educational interventions, where the age of intervention appears to be important, as it is for IPV 
interventions that tend to enrol predominantly adult cohorts. All interventions should ensure sufficient statistical power to stratify results by gender. A further noteworthy challenge of structural interventions with adolescents is the need for parental consent to participate, and the potential for the most vulnerable young people to be excluded from either the intervention or the evaluation process, because they cannot gain parental consent, thereby impacting the generalizability of the findings.

The evaluation of interventions in a more diverse set of countries would further contribute to our understanding of the contextual sensitivities of some of these interventions. Evidence on livelihood interventions, particularly in East Africa, derives substantially from OVC households; applying lessons from OVC interventions to other vulnerable groups of young people, including out-of-school youth and young married women, could yield additional valuable evidence. Evaluations of government social protection programmes were particularly valuable in this review. As governments in sub-Saharan Africa expand social protection programming, there is the potential to evaluate the impact on structural drivers of HIV and on HIV infection among young people.

Finally, the most important challenge for the future is to move evidence into practice. Improving educational attainment, reducing poverty, challenging restricting and harmful gender norms and mitigating the risk of gender-based violence are important steps to interrupt the causal pathway towards HIV infection. The evidence supports a multi-sectoral approach for multiple outcomes. Such approaches need to be integrated into HIV prevention, gender empowerment and broader development initiatives in line with the SDG priorities. To achieve this, we need further evidence on the best mechanisms to achieve scale, integration into existing programmes and sustained effectiveness. We also need more information on the implementation of cross-sectoral co-financing as an innovative strategy to support upstream interventions that yield multiple benefits, thus increasing efficiency in the allocation of government, donor and other budget holders' resources. The priority must be the implementation of high-impact interventions that can achieve multiple health and social impacts for young people in the process of mitigating the risk of HIV and achieving costefficiencies across the interconnected SDGs.

\section{References}

Abdool-Karim, Q., Leask, K., Kharsany, A., Humphries, H., Ntombela, F., Samsunder, N., Baxter, C., Frohlich, J., Van Der Elst, L. \& Abdool-Karim, S. 2015. Impact of conditional cash incentives on HSV-2 and HIV prevention in rural South African high school students: Results of the CAPRISA 007 cluster randomized controlled trial. Journal of the International AIDS Society, 18.

Abramsky, T., Devries, K., Kiss, L., Nakuti, J., Kyegombe, N., Starmann, E., Cundill, B., Francisco, L., Kaye, D., Musuya, T., Michau, L. \& Watts, C. 2014. Findings from the SASA! Study: A cluster randomized controlled trial to assess the impact of 
a community mobilization intervention to prevent violence against women and reduce HIV risk in Kampala, Uganda. BMC Medicine, 12, 122.

Baird, S.J., Ferreira, H. G., Özler, B. \& Woolcock, M. 2013. Relative effectiveness of conditional and unconditional cash transfers for schooling outcomes in developing countries: A systematic review. Campbell Systematic Reviews, 8.

Baird, S.J., Garfein, R. S., Mcintosh, C. T. \& Özler, B. 2012. Effect of a cash transfer programme for schooling on prevalence of HIV and herpes simplex type 2 in Malawi: A cluster randomised trial. Lancet, 379, 1320-1329.

Bandiera, O., Buehren, N., Burgess, R., Goldstein, M., Gulesci, S., Rasul, I. \& Sulaiman, M. 2012. Empowering adolescent girls: Evidence from a randomized control trial in Uganda. Semantics Scholar. [Online] Available: http://econ.lse.ac.uk/ staff/rburgess/wp/ELA.pdf

Barnighausen, T., Hosegood, V., Timaeus, I. M. \& Newell, M. L. 2007. The socioeconomic determinants of HIV incidence: Evidence from a longitudinal, populationbased study in rural South Africa. AIDS, 21 Suppl 7, S29-S38.

Blankenship, K. M., Bray, S.J. \& Merson, M. H. 2000. Structural interventions in public health. AIDS, 14 Suppl 1, S11-S21.

Bruce, J. 2015. Commentary: Investing in the poorest girls in the poorest communities early enough to make a difference. Global Public Health, 10, 225-227.

Buller, A. M., Peterman, A., Ranganathan, M., Bleile, A., Hidrobo, M. \& Heise, L. 2018. A mixed-method review of cash transfers and intimate partner violence in low and middle-income countries. London: STRIVE, London School of Hygiene and Tropical Medicine.

Chatterji, M., Hutchinson, P., Buek, K., Murray, N., Mulenga, Y. \& Ventimiglia, T. 2010. Evaluating the impact of community-based interventions on schooling outcomes among orphans and vulnerable children in Lusaka, Zambia. Vulnerable Children and Youth Studies, 5, 130-141.

Cho, H., Hallfors, D. D., Mbai, II, Itindi, J., Milimo, B. W., Halpern, C. T. \& Iritani, B.J. 2011. Keeping adolescent orphans in school to prevent human immunodeficiency virus infection: Evidence from a randomized controlled trial in Kenya. Journal of Adolescent Health, 48, 523-526.

Cho, H., Mbai, I., Luseno, W.K., Hobbs, M., Halpern, C. \& Hallfors, D. D. 2018. School support as structural HIV prevention for adolescent orphans in Western Kenya. Journal of Adolescent Health, 62, 44-51.

Cho, H., Ryberg, R. C., Hwang, K., Pearce, L. D. \& Iritani, B. J. 2017. A school support intervention and educational outcomes among orphaned adolescents: Results of a cluster randomized controlled trial in Kenya. Prevention Science, 18, 943-954.

Cislaghi, B. \& Heise, L. 2016. Measuring gender-related social norms, learning report 1. Learning group on social norms and gender-related harmful practices. London: STRIVE, London School of Hygiene and Tropical Medicine.

Cislaghi, B., Heise, L., 2017. STRIVE technical brief: Measuring social norms. London: STRIVE, London School of Hygiene and Tropical Medicine.

Cislaghi, B., Manji, K. \& Heise, L. 2018. Social norms and gender-related harmful practices. Learning report 2: Theory in support of better practice. Learning Group on Social Norms and Gender- related Harmful Practices. London: STRIVE, London School of Hygiene and Tropical Medicine.

Cluver, L. D., Boyes, M., Orkin, M., Pantelic, M., Molwena, T. \& Sherr, L. 2013. Childfocused state cash transfers and adolescent risk of HIV infection in South Africa: A propensity-score-matched case-control study. Lancet Global Health, 1, e362-e370. 
Cluver, L.D., Orkin, F. M., Yakubovich, A. R. \& Sherr, L. 2016. Combination social protection for reducing HIV-risk behavior among adolescents in South Africa. Journal of Acquired Immune Deficiency Syndromes: JAIDS, 72, 96-104.

Cowan, F. M., Pascoe, S.J., Langhaug, L. F., Mavhu, W., Chidiya, S., Jaffar, S., Mbizvo, M. T., Stephenson, J.M., Johnson, A. M., Power, R. M., Woelk, G., Hayes, R.J. \& Regai Dzive Shiri Trial, T. 2010. The Regai Dzive Shiri project: Results of a randomized trial of an HIV prevention intervention for youth. AIDS, 24, 2541-2552.

Curley, J., Ssewamala, F. \& Han, C. K. 2010. Assets and educational outcomes: Child development accounts (CDAs) for orphaned children in Uganda. Children and Youth Services Review, 32, 1585-1590.

De Koker, P., Mathews, C., Zuch, M., Bastien, S. \& Mason-Jones, A.J. 2014. A systematic review of interventions for preventing adolescent intimate partner violence. Journal of Adolescent Health, 54, 3-13.

De Neve, J.W., Fink, G., Subramanian, S.V., Moyo, S. \& Bor, J. 2015. Length of secondary schooling and risk of HIV infection in Botswana: Evidence from a natural experiment. Lancet Global Health, 3, e470-e477.

De Oliveira, T., Kharsany, A., Gräf, T., Cawood, C., Khanyile, D., Grobler, A., Puren, A., Madurai, S., Baxter, C., Karim, Q. \& Karim, S. 2017. Transmission networks and risk of HIV infection in KwaZulu-Natal, South Africa: A community-wide phylogenetic study. Lancet HIV, 4, e41-e50.

Decker, M.R., Seage, G. R., 3rd, Hemenway, D., Raj, A., Saggurti, N., Balaiah, D. \& Silverman, J. G. 2009. Intimate partner violence functions as both a risk marker and risk factor for women's HIV infection: Findings from Indian husband-wife dyads. Journal of Acquired Immune Deficiency Syndrome, 51, 593-600.

Delany-Moretlwe, S., Hargreaves, J., Stangl, A., Gafos, M. 2018. STRIVE technical brief: Biomedical and structural prevention: STRIVE in the era of 'cascades'. London: STRIVE, London School of Hygiene and Tropical Medicine.

Delva, W., Michielsen, K., Meulders, B., Groeninck, S., Wasonga, E., Ajwang, P., Temmerman, M. \& Vanreusel, B. 2010. HIV prevention through sport: The case of the Mathare Youth Sport Association in Kenya. Aids Care-Psychological and SocioMedical Aspects of AIDS/HIV, 22, 1012-1020.

Dunbar, M.S., Kang Dufour, M.S., Lambdin, B., Mudekunye-Mahaka, I., Nhamo, D. \& Padian, N. S. 2014. The SHAZ! project: Results from a pilot randomized trial of a structural intervention to prevent HIV among adolescent women in Zimbabwe. PLoS One [Electronic Resource], 9, e113621.

Dunkle, K. L. \& Decker, M.R. 2013. Gender-based violence and HIV: Reviewing the evidence for links and causal pathways in the general population and high-risk groups. American Journal of Reproductive Immunology, 69 Suppl 1, 20-26.

Dunkle, K. L., Jewkes, R.K., Nduna, M., Levin, J., Jama, N., Khuzwayo, N., Koss, M. P. \& Duvvury, N. 2006. Perpetration of partner violence and HIV risk behaviour among young men in the rural Eastern Cape, South Africa. AIDS, 20, 2107-2114.

Durevall, D. \& Lindskog, A. 2015a. Intimate partner violence and HIV in ten subSaharan African countries: What do the demographic and health surveys tell us? Lancet Global Health, 3, e34-e43.

Durevall, D. \& Lindskog, A. 2015b. Intimate partner violence and HIV infection in sub-Saharan Africa. World Development, 72, 27-42.

Dworkin, S.L., Treves-Kagan, S. \& Lippman, S.A. 2013. Gender-transformative interventions to reduce HIV risks and violence with heterosexually-active men: A review of the global evidence. AIDS and Behavior, 17, 2845-2863. 
Ellsberg, M., Arango, D.J., Morton, M., Gennari, F., Kiplesund, S., Contreras, M. \& Watts, C. 2015. Prevention of violence against women and girls: What does the evidence say? Lancet, 385, 1555-1566.

Fenton, R., Nyamukapa, C., Gregson, S., Robertson, L., Mushati, P., Thomas, R. \& Eaton, J.W. 2016. Wealth differentials in the impact of conditional and unconditional cash transfers on education: Findings from a community-randomised controlled trial in Zimbabwe. Psychology, Health $\mathcal{E}$ Medicine, 21, 909-917.

Fox, A. M. 2010. The social determinants of HIV serostatus in sub-Saharan Africa: An inverse relationship between poverty and HIV? Public Health Reports, 125 Suppl $4,16-24$.

Fritz, K. \& Heise, L. 2018. STRIVE technical brief: A moment of convergence: STRIVE and the sustainable development goals. London: STRIVE, London School of Hygiene and Tropical Medicine.

Gass, J.D., Stein, D.J., Williams, D. R. \& Seedat, S. 2011. Gender differences in risk for intimate partner violence among South African adults. Journal of Interpersonal Violence, 26, 2764-2789.

Gibbs, A., Jacobson, J. \& Kerr Wilson, A. 2017. A global comprehensive review of economic interventions to prevent intimate partner violence and HIV risk behaviours. Global Health Action, 10, 1290427.

Gibbs, A., Willan, S., Misselhorn, A. \& Mangoma, J. 2012. Combined structural interventions for gender equality and livelihood security: A critical review of the evidence from southern and eastern Africa and the implications for young people. Journal of the International Aids Society, 15.

Gillespie, S., Kadiyala, S. \& Greener, R. 2007. Is poverty or wealth driving HIV transmission? AIDS, 21 Suppl 7, S5-S16.

Goodman, M.L., Kaberia, R., Morgan, R. O. \& Keiser, P.H. 2014. Health and livelihood outcomes associated with participation in a community-based empowerment program for orphan families in semirural Kenya: A cross-sectional study. Vulnerable Children and Youth Studies, 9, 365-376.

Gupta, G. R., Parkhurst, J. O., Ogden, J.A., Aggleton, P. \& Mahal, A. 2008. Structural approaches to HIV prevention. Lancet, 372, 764-775.

Hallfors, D., Cho, H., Mbai, I., Milimo, B. \& Itindi, J. 2012. Process and outcome evaluation of a community intervention for orphan adolescents in western Kenya. Journal of Community Health, 37, 1101-1109.

Hallfors, D., Cho, H., Rusakaniko, S., Iritani, B., Mapfumo, J. \& Halpern, C. 2011. Supporting adolescent orphan girls to stay in school as HIV risk prevention: Evidence from a randomized controlled trial in Zimbabwe. American Journal of Public Health, 101, 1082-1088.

Hallfors, D., Cho, H., Rusakaniko, S., Mapfumo, J., Iritani, B., Zhang, L., Luseno, W. \& Miller, T. 2015. The impact of school subsidies on HIV-related outcomes among adolescent female orphans. Journal of Adolescent Health, 56, 79-84.

Hallman, K. 2005a. The effects of orphaning and poverty on sexual debut in KwaZulu-Natal, South Arica. IUSSP Seminar on "Poverty and HIV/ AIDS". Cape Town, South Africa: University of Cape Town.

Hallman, K. 2005b. Gendered socioeconomic conditions and HIV risk behaviours among young people in South Africa. African Journal of AIDS Research, 4, 37-50.

Handa, S., Halpern, C.T., Pettifor, A. \& Thirumurthy, H. 2014. The government of Kenya's cash transfer program reduces the risk of sexual debut among young people age 15-25. PLoS One [Electronic Resource], 9, e85473. 
Handa, S., Peterman, A., Huang, C., Halpern, C., Pettifor, A. \& Thirumurthy, H. 2015. Impact of the Kenya cash transfer for orphans and vulnerable children on early pregnancy and marriage of adolescent girls. Social Science E Medicine, 141, 36-45.

Hankins, C.A. \& De Zalduondo, B. O. 2010. Combination prevention: A deeper understanding of effective HIV prevention. AIDS, 24 Suppl 4, S70-S80.

Hardee, K., Gay, J., Croce-Galis, M. \& Peltz, A. 2014. Strengthening the enabling environment for women and girls: What is the evidence in social and structural approaches in the HIV response? Journal of the International AIDS Society, 17, 18619.

Hargreaves, J. R. 2002. Socioeconomic status and risk of HIV infection in an urban population in Kenya. Tropical Medicine $\mathcal{E}$ International Health, 7, 793-802.

Hargreaves, J. R., Bonell, C. P., Boler, T., Boccia, D., Birdthistle, I., Fletcher, A., Pronyk, P. M. \& Glynn, J. R. 2008. Systematic review exploring time trends in the association between educational attainment and risk of HIV infection in sub-Saharan Africa. AIDS, 22, 403-414.

Hargreaves, J. R. \& Glynn, J. R. 2002. Educational attainment and HIV-1 infection in developing countries: A systematic review. Tropical Medicine $\mathcal{E}$ International Health, 7, 489-498.

Harrison, A., O’Sullivan, L. F., Hoffman, S., Dolezal, C. \& Morrell, R. 2006. Gender role and relationship norms among young adults in South Africa: Measuring the context of masculinity and HIV risk. Journal of Urban Health, 83, 709-722.

Heise, L. \& Hossain, M. 2017. STRIVE technical brief: Measuring intimate partner violence. London: STRIVE, London School of Hygiene and Tropical Medicine.

Heise, L., Lutz, B., Ranganathan, M. \& Watts, C. 2013. Cash transfers for HIV prevention: Considering their potential. Journal of the International Aids Society, 16.

Heise, L. \& McGrory, E. 2016. Violence against women and girls and HIV: Report on a high level consultation on the evidence and its implications, 12-14 May, 2015. Greentree Estate. London: STRIVE Research Consortium.

Iritani, B.J., Cho, H., Rusakaniko, S., Mapfumo, J., Hartman, S. \& Hallfors, D. D. 2016. Educational outcomes for orphan girls in rural Zimbabwe: Effects of a school support intervention. Health Care for Women International, 37, 301-322.

Ismayilova, L., Ssewamala, F. M. \& Karimli, L. 2012. Family support as a mediator of change in sexual risk-taking attitudes among orphaned adolescents in rural Uganda. Journal of Adolescent Health, 50, 228-235.

Jennings, L., Ssewamala, F. M. \& Nabunya, P. 2016. Effect of savings-led economic empowerment on HIV preventive practices among orphaned adolescents in rural Uganda: Results from the Suubi-Maka randomized experiment. AIDS Care, 28, 273-282.

Jewkes, R., Dunkle, K., Nduna, M. \& Shai, N. 2010. Intimate partner violence, relationship power inequity, and incidence of HIV infection in young women in South Africa: A cohort study. Lancet, 376, 41-48.

Jewkes, R., Flood, M. \& Lang, J. 2015. From work with men and boys to changes of social norms and reduction of inequities in gender relations: A conceptual shift in prevention of violence against women and girls. Lancet, 385, 1580-1589.

Jewkes, R., Gibbs, A., Jama-Shai, N., Willan, S., Misselhorn, A., Mushinga, M., Washington, L., Mbatha, N. \& Sikweyiya, Y. 2014. Stepping Stones and Creating Futures intervention: Shortened interrupted time series evaluation of a behavioural and structural health promotion and violence prevention intervention for young people in informal settlements in Durban, South Africa. BMC Public Health, 14.

Jewkes, R., Nduna, M., Levin, J., Jama, N., Dunkle, K., Puren, A. \& Duvvury, N. 2008. Impact of stepping stones on incidence of HIV and HSV-2 and sexual behaviour 
in rural South Africa: Cluster randomised controlled trial. British Medical Journal, 337, a506.

Jewkes, R., Sikweyiya, Y., Morrell, R. \& Dunkle, K. 2011. The relationship between intimate partner violence, rape and HIV amongst South African men: A crosssectional study. PLoS One, 6, e24256.

Jukes, M., Simmons, S. \& Bundy, D. 2008a. Education and vulnerability: The role of schools in protecting young women and girls from HIV in southern Africa. AIDS, 22 Suppl 4, S41-S56.

Jukes, M., Simmons, S. \& Bundy, D. 2008b. Education and vulnerability: The role of schools in protecting young women and girls from HIV in southern Africa (Vulnerability of young women and girls to HIV infection in the hyperendemic countries of southern Africa.). AIDS, 22, S41-S56.

Kacanek, D., Bostrom, A., Montgomery, E. T., Ramjee, G., De Bruyn, G., Blanchard, K., Rock, A., Mtetwa, S., Van Der Straten, A. \& Team, M. 2013. Intimate partner violence and condom and diaphragm nonadherence among women in an HIV prevention trial in southern Africa. Journal of Acquired Immune Deficiency Syndrome, $64,400-408$.

Kaufman, M. R., Mooney, A., Kamala, B., Modarres, N., Karam, R. \& Ng'wanansabi, D. 2013a. Effects of the Fataki campaign: Addressing cross-generational sex in Tanzania by mobilizing communities to intervene. AIDS Behaviour, 17, 2053-2062.

Kaufman, Z.A., E B Kaufman, E.B., Dringus, S., Weiss, H.A., Delany-Moretlwe, S. \& Ross, D.A. 2013b. Baseline results: Of a cluster-randomised trial assessing the effectiveness of sport-based HIV prevention in South African schools. Sexually Transmitted Infections, 89, A1-A428.

Kennedy, C. E., Fonner, V.A., O’Reilly, K. R. \& Sweat, M. D. 2014. A systematic review of income generation interventions, including microfinance and vocational skills training, for HIV prevention. AIDS Care, 26, 659-673.

Kinghorn, A., Shanaube, K., Toska, E., Cluver, C. \& Bekker, L. 2018. Defining adolescence: Priorities from a global health perspective. Lancet: Child and Adolescent Health, 2(5), e10.

Kippax, S. 2008. Understanding and integrating the structural and biomedical determinants of HIV infection: A way forward for prevention. Current Opinion in HIV E् AIDS, 3, 489-494.

Krishnaratne, S., Hensen, B., Cordes, J., Enstone, J. \& Hargreaves, J. R. 2016. Interventions to strengthen the HIV prevention cascade: A systematic review of reviews. Lancet HIV, 3, e307-e317.

Krumpal, I. 2013. Determinants of social desirability bias in sensitive surveys: A literature review. Quality $\mathcal{E}^{2}$ Quantity, 47.

Lloyd, C.B. \& Mensch, B.S. 2008. Marriage and childbirth as factors in dropping out from school: An analysis of DHS data from sub-Saharan Africa. Population Studies (Camb), 62, 1-13.

Lorenzetti, L. M. J., Leatherman, S. \& Flax, V.L. 2017. Evaluating the effect of integrated microfinance and health interventions: An updated review of the evidence. Health Policy and Planning, 32, 732-756.

Luke, N. 2003. Age and economic asymmetries in the sexual relationships of adolescent girls in sub-Saharan Africa. Studies in Family Planning, 34, 67-86.

Luke, N. 2005. Confronting the 'sugar daddy' stereotype: Age and economic asymmetries and risky sexual behavior in urban Kenya. International Family Planning Perspective, 31, 6-14. 
Lundgren, R. \& Amin, A. 2015. Addressing intimate partner violence and sexual violence among adolescents: Emerging evidence of effectiveness. Journal of Adolescent Health, 56, S42-S50.

Maman, S., Campbell, J., Sweat, M. D. \& Gielen, A. C. 2000. The intersections of HIV and violence: Directions for future research and interventions. Social Science $\mathcal{F}^{\circ}$ Medicine, 50, 459-78.

Mason-Jones, A.J., Sinclair, D., Mathews, C., Kagee, A., Hillman, A. \& Lombard, C. 2016. School-based interventions for preventing HIV, sexually transmitted infections, and pregnancy in adolescents. Cochrane Database of Systematic Reviews, 11, CD006417.

Mathews, C., Eggers, S., Townsend, L., Aarø, L., Vries, P., Mason-Jones, A., Koker, P., McClinton Appollis, T., Mtshizana, Y., Koech, J., Wubs, A. \& Vries, H. 2016. Effects of prepare, a multi-component, school-based HIV and intimate partner violence (IPV) prevention programme on adolescent sexual risk behaviour and IPV: Cluster randomised controlled trial. AIDS E Behavior, 20, 1821-1840.

McCloskey, L.A., Boonzaier, F., Steinbrenner, S.Y. \& Hunter, T. 2016. Determinants of intimate partner violence in sub-Saharan Africa: A review of prevention and intervention programs. Partner Abuse, 7, 277-315.

Mishra, V., Assche, S. B., Greener, R., Vaessen, M., Hong, R., Ghys, P. D., Boerma, J. T., Van Assche, A., Khan, S. \& Rutstein, S. 2007. HIV infection does not disproportionately affect the poorer in sub-Saharan Africa. AIDS, 21 Suppl 7, S17-S28.

Parcesepe, A. M., Engle, K. L. L., Martin, S. L., Green, S., Sinkele, W., Suchindran, C., Speizer, I. S., Mwarogo, P. \& Kingola, N. 2016. The impact of an alcohol harm reduction intervention on interpersonal violence and engagement in sex work among female sex workers in Mombasa, Kenya: Results from a randomized controlled trial. Drug Ẽ Alcohol Dependence, 161, 21-28.

Parkhurst, J. O. 2010. Understanding the correlations between wealth, poverty and human immunodeficiency virus infection in African countries. Bulletin of the World Health Organization, 88, 519-526.

Parkhurst, J. O. 2013. Structural drivers, interventions, and approaches for prevention of sexually transmitted HIV in general populations: Definitions and an operational approach. Structural Approaches to HIV Prevention Position Paper Series. London: STRIVE, London School of Hygiene and Tropical Medicine.

Patton, G. C., Sawyer, S. M., Santelli, J.S., Ross, D.A., Afifi, R., Allen, N. B., Arora, M., Azzopardi, P., Baldwin, W., Bonell, C., Kakuma, R., Kennedy, E., Mahon, J., McGovern, T., Mokdad, A.H., Patel, V., Petroni, S., Reavley, N., Taiwo, K., Waldfogel, J., Wickremarathne, D., Barroso, C., Bhutta, Z., Fatusi, A. O., Mattoo, A., Diers, J., Fang, J., Ferguson, J., Ssewamala, F. \& Viner, R. M. 2016. Our future: A Lancet commission on adolescent health and wellbeing. Lancet, 387, 2423-2478.

Pega, F., Liu, S.Y., Walter, S., Pabayo, R., Saith, R. \& Lhachimi, S. K. 2017. Unconditional cash transfers for reducing poverty and vulnerabilities: Effect on use of health services and health outcomes in low- and middle-income countries. Cochrane Database of Systematic Reviews, (11), Art. No.: CD011135.

Pettifor, A., Levandowski, B.A., Macphail, C., Padian, N.S., Cohen, M.S. \& Rees, H.V. 2008. Keep them in school: The importance of education as a protective factor against HIV infection among young South African women. International Journal of Epidemiology, 37, 1266-1273.

Pettifor, A., Macphail, C., Hughes, J.P., Selin, A., Wang, J., Gomez-Olive, F. X., Eshleman, S.H., Wagner, R.G., Mabuza, W., Khoza, N., Suchindran, C., Mokoena, I., Twine, R., Andrew, P., Townley, E., Laeyendecker, O., Agyei, Y., Tollman, S. \& 
Kahn, K. 2016. The effect of a conditional cash transfer on HIV incidence in young women in rural South Africa (HPTN 068): A phase 3, randomised controlled trial. Lancet Global Health, 4, e978-e988.

Pinkerton, S. D., Layde, P. M. \& NIMH Multisite HIV Prevention Trial Group. 2002. Using sexually transmitted disease incidence as a surrogate marker for HIV incidence in prevention trials: A modeling study. Sexually Transmitted Diseases, 29, 298-307.

Pronyk, P. M., Hargreaves, J. R., Kim, J. C., Morison, L.A., Phetla, G., Watts, C., Busza, J. \& Porter, J.D. 2006. Effect of a structural intervention for the prevention of intimate-partner violence and HIV in rural South Africa: A cluster randomised trial. Lancet, 368, 1973-1983.

Prudden, H. 2017. Incorporating structural interventions in country HIV programme planning and resource allocation: Report from an expert consultation convened by STRIVE and the HIV modelling consortium with support from the global fund to fight AIDS, Tuberculosis and Malaria. London: STRIVE, London School of Hygiene and Tropical Medicine.

Remme, M. \& McGuire, F. 2018. STRIVE technical brief: Development synergies and cofinancing. London: STRIVE, London School of Hygiene and Tropical Medicine.

Remme, M., Vassall, A., Lutz, B., Luna, J. \& Watts, C. 2014. Financing structural interventions: Going beyond HIV-only value for money assessments. AIDS, 28, $425-434$.

Remme, M., Vassall, A., Lutz, B. \& Watts, C. 2012. Paying girls to stay in school: A good return on HIV investment? Lancet, 379, 2150.

Robertson, L., Mushati, P., Eaton, J.W., Dumba, L., Mavise, G., Makoni, J., Schumacher, C., Crea, T., Monasch, R., Sherr, L., Garnett, G.P., Nyamukapa, C. \& Gregson, S. 2013. Effects of unconditional and conditional cash transfers on child health and development in Zimbabwe: A cluster-randomised trial. Lancet, 381, 1283-1292.

Rotheram-Borus, M.J., Lightfoot, M., Kasirye, R. \& Desmond, K. 2012. Vocational training with HIV prevention for Ugandan youth. AIDS E Behavior, 16, 1133-1137.

Sarnquist, C., Omondi, B., Sinclair, J., Gitau, C., Paiva, L., Mulinge, M., Cornfield, D. N. \& Maldonado, Y. 2014. Rape prevention through empowerment of adolescent girls. Pediatrics, 133, e1226-e1232.

Seeley, J., Watts, C. H., Kippax, S., Russell, S., Heise, L. \& Whiteside, A. 2012. Addressing the structural drivers of HIV: A luxury or necessity for programmes? Journal of International AIDS Society, 15 Suppl 1, 1-4.

Shai, N.J. \& Sikweyiya, Y. 2015. Programmes for change addressing sexual and intimate partner violence in South Africa. South African Crime Quarterly, 31-41.

Sherr, L., Tomlinson, M., Macedo, A., Skeen, S., Hensels, I. S. \& Cluver, L. D. 2017. Can cash break the cycle of educational risks for young children in high HIVaffected communities? A cross-sectional study in South Africa and Malawi. Journal of Global Health, 7.

Ssewamala, F. M., Han, C. K. \& Neilands, T. B. 2009. Asset ownership and health and mental health functioning among AIDS-orphaned adolescents: Findings from a randomized clinical trial in rural Uganda. Social Science Ev Medicine, 69, 191-198.

Ssewamala, F.M., Karimli, L., Torsten, N., Wang, J.S., Han, C.K., Ilic, V. \& Nabunya, P. 2016. Applying a family-level economic strengthening intervention to improve education and health-related outcomes of school-going AIDS-orphaned children: Lessons from a randomized experiment in Southern Uganda. Prevention Science, 17, 134-143. 
Ssewamala, F. M., Han, C. K., Neilands, T. B., Ismayilova, L. \& Sperber, E. 2010a. Effect of economic assets on sexual risk-taking intentions among orphaned adolescents in Uganda. American Journal of Public Health, 100(3), 483-488. doi:10.2105/ AJPH.2008.158840

Ssewamala, F. M., Ismayilova, L., McKay, M., Sperber, E., Bannon, W. Jr. \& Alicea, S. 2010b. Gender and the effects of an economic empowerment program on attitudes toward sexual risk-taking among AIDS-orphaned adolescent youth in Uganda. Journal of Adolescent Health, 46(4), 372-378.

Ssewamala, F. M., Neilands, T.B., Waldfogel, J. \& Ismayilova, L. 2012. The impact of a comprehensive microfinance intervention on depression levels of AIDSorphaned children in Uganda. Journal of Adolescent Health, 50, 346-352.

Stangl, A., Brady, L. \& Fritz, K. 2017. STRIVE technical brief: Measuring HIV stigma and discrimination. Washington, DC: International Center for Research on Women.

Stangl, A., Lloyd, J.K., Brady, L.M., Holland, C.E. \& Baral, S. 2013. A systematic review of interventions to reduce HIV-related stigma and discrimination from 2002 to 2013: How far have we come? Journal of International AIDS Society, 16, 18734.

Stangl, A. \& Sievwright, K. 2016. HIV-related stigma and children. In: Chenneville, T. (ed.) A clinical guide to pediatric HIV: Bridging the gaps between research and practice. New York: Springer.

Stangl, A., Singh, D., Windle, M., Sievwright, K., Footer, K., Iovita, A., Mukasa, S., Baral, S. in press. A systematic review of human rights programs to improve HIVrelated outcomes from 2003 to 2015: What do we know? BMC Infectious Diseases.

Stoebenau, K., Heise, L., Wamoyi, J. \& Bobrova, N. 2016. Revisiting the understanding of "transactional sex" in sub-Saharan Africa: A review and synthesis of the literature. Social Science Ẽ Medicine, 168, 186-197.

Stroeken, K., Remes, P., De Koker, P., Michielsen, K., Van Vossole, A. \& Temmerman, M. 2012. HIV among out-of-school youth in Eastern and Southern Africa: A review. AIDS Care, 24, 186-194.

Svanemyr, J., Amin, A., Robles, O.J. \& Greene, M.E. 2015. Creating an enabling environment for adolescent sexual and reproductive health: A framework and promising approaches. Journal of Adolescent Health, 56, S7-S14.

Taaffe, J.E., Cheikh, N. \& Wilson, D. 2016. The use of cash transfers for HIV prevention - are we there yet? African Journal of AIDS Research, 15, 17-25.

Taaffe, J.E., Longosz, A. F. \& Wilson, D. 2017. The impact of cash transfers on livelihoods, education, health and HIV - what's the evidence? Development Policy Review, 35, 601-619.

UN. 2016. Sustainable development goals. [Online] Available: https://sustainabledevelopment.un.org

UNAIDS. 2015. On the fast-track to end AIDS: 2016-2021 strategy. Geneva: UNAIDS.

UNAIDS. 2018a. Social protection: A fast-track commitment to end AIDS. Guidance for policy-makers, and people living with, at risk of or affected by HIV. Geneva: UNAIDS.

UNAIDS. 2018b. Women and girls and HIV. Geneva: UNAIDS.

UNAIDS/STRIVE. 2018. Transactional sex and HIV risk: From analysis to action. Geneva: Joint United Nations Programme on HIV/AIDS and STRIVE.

UNICEF. 2018. Turning the tide against AIDS will require more concentrated focus on adolescents and young people. [Online] Available: https://data.unicef.org/topic/ hivaids/adolescents-young-people/

Vassall, A. \& Remme, M., 2018. STRIVE impact case study: Cross-sectoral co-financing for HIV and development synergies. London: STRIVE, London School of Hygiene and Tropical Medicine. 
Wagman, J.A., Gray, R.H., Campbell, J.C., Thoma, M., Ndyanabo, A., Ssekasanvu, J., Nalugoda, F., Kagaayi, J., Nakigozi, G., Serwadda, D. \& Brahmbhatt, H. 2015. Effectiveness of an integrated intimate partner violence and HIV prevention intervention in Rakai, Uganda: Analysis of an intervention in an existing cluster randomised cohort. Lancet Global Health, 3, e23-e33.

Wamoyi, J., Mshana, G., Mongi, A., Neke, N., Kapiga, S. \& Changalucha, J. 2014. A review of interventions addressing structural drivers of adolescents' sexual and reproductive health vulnerability in sub-Saharan Africa: Implications for sexual health programming. Reproductive Health, 11.

Wamoyi, J., Stobeanau, K., Bobrova, N., Abramsky, T. \& Watts, C. 2016. Transactional sex and risk for HIV infection in sub-Saharan Africa: A systematic review and meta-analysis. Journal of International AIDS Society, 19, 20992.

Wamoyi, J., Stoebenau, K., Kyegombe, N., Heise, L. \& Ranganathan, M. 2017. STRIVE Technical brief: Measuring transactional sex and HIV risk. Tanzania: National Institute of Medical Research, Mwanza; Washington, DC: International Center for Research on Women; London: London School of Hygiene and Tropical Medicine.

Wechsberg, W., Jewkes, R., Novak, S.P., Kline, T., Myers, B., Browne, F.A., Carney, T., Morgan Lopez, A. A. \& Parry, C. 2013. A brief intervention for drug use, sexual risk behaviours and violence prevention with vulnerable women in South Africa: A randomised trial of the women's health CoOp. BMJ Open, 3.

Wechsberg, W., Zule, W., Luseno, W., Kline, T., Browne, F., Novak, S. \& MiddlesteadtEllerson, R. 2011. Effectiveness of an adapted evidence-based woman-focused intervention for sex workers and non-sex workers: The women's health $\mathrm{CoOp}$ in South Africa. Journal of Drug Issues, 41, 233-252.

Wilson, D. 2015. Social protection, financial incentives, and prevention of HIV. Topics in Antiviral Medicine, 23, 30-31.

Wojcicki, J.M. 2005. Socioeconomic status as a risk factor for HIV infection in women in East, Central and Southern Africa: A systematic review. Journal of Biosocial Science, 37, 1-36.

Woodcock, A., Cronin, O. \& Forde, S. 2012. Quantitative evidence for the benefits of moving the goalposts, a sport for development project in rural Kenya. Evaluation E Program Planning, 35, 370-381.

Zuilkowski, S.S. \& Alon, I. 2015. Promoting education for vulnerable children by supporting families: A holistic intervention in Uganda. Journal of Social Service Research, 41, 454-465. 